\title{
Ozone loss and chlorine activation in the Arctic winters 1991-2003 derived with the tracer-tracer correlations
}

\author{
S. Tilmes ${ }^{1}$, R. Müller ${ }^{1}$, J.-U. Grooß ${ }^{1}$, and J. M. Russell III ${ }^{2}$ \\ ${ }^{1}$ Institute of Stratospheric Research (ICG-I), Forschungszentrum Jülich, Germany \\ ${ }^{2}$ Hampton University, Hampton, Virginia 23668, USA \\ Received: 11 March 2004 - Published in Atmos. Chem. Phys. Discuss.: 4 May 2004 \\ Revised: 22 July 2004 - Accepted: 1 August 2004 - Published: 15 November 2004
}

\begin{abstract}
Chemical ozone loss in the Arctic stratosphere was investigated for the twelve years between 1991 and 2003 employing the ozone-tracer correlation method. For this method, the change in the relation between ozone and a longlived tracer is considered for all twelve years over the lifetime of the polar vortex to calculate chemical ozone loss. Both the accumulated local ozone loss in the lower stratosphere and the column ozone loss were derived consistently, mainly on the basis of HALOE satellite observations. HALOE measurements do not cover the polar region homogeneously over the course of the winter. Thus, to derive an early winter reference function for each of the twelve years, all available measurements were additionally used; for two winters climatological considerations were necessary. Moreover, a detailed quantification of uncertainties was performed. This study further demonstrates the interaction between meteorology and ozone loss. The connection between temperature conditions and chlorine activation, and in turn, the connection between chlorine activation and ozone loss, becomes obvious in the HALOE HCl measurements. Additionally, the degree of homogeneity of ozone loss within the vortex was shown to depend on the meteorological conditions.

Results derived here are in general agreement with the results obtained by other methods for deducing polar ozone loss. Differences occur mainly owing to different time periods considered in deriving accumulated ozone loss. However, very strong ozone losses as deduced from SAOZ for January in winters 1993-1994 and 1995-1996 cannot be identified using available HALOE observations in the early winter. In general, strong accumulated ozone loss was found to occur in conjunction with a strong cold vortex containing a large volume of possible PSC existence ( $\mathrm{V}_{\mathrm{PSC}}$ ), whereas moderate ozone loss was found if the vortex was less strong and moderately warm. Hardly any ozone loss was calculated
\end{abstract}

Correspondence to: $\mathrm{S}$. Tilmes

(simone.tilmes@t-online.de) for very warm winters with small amounts of $\mathrm{V}_{\text {PSC }}$ during the entire winter. This study supports the linear relationship between $\mathrm{V}_{\mathrm{PSC}}$ and the accumulated ozone loss reported by Rex et al. (2004) if $V_{\text {PSC }}$ was averaged over the entire winter period. Here, further meteorological factors controlling ozone loss were additionally identified if $\mathrm{V}_{\mathrm{PSC}}$ was averaged over the same time interval as that for which the accumulated ozone loss was deduced. A significant difference in ozone loss (of $\approx 36 \mathrm{DU}$ ) was found due to the different duration of solar illumination of the polar vortex of at maximum 4 hours per day in the observed years. Further, the increased burden of aerosols in the atmosphere after the Pinatubo volcanic eruption in 1991 significantly increased the extent of chemical ozone loss.

\section{Introduction}

The mixing ratio of stratospheric ozone in the Arctic vortex is determined by both chemical reactions and by transport. In particular, the most prominent transport process inside the polar vortex is the diabatic descent of air during winter. Descent of air tends to increase the ozone mixing ratio at a given altitude, because ozone mixing ratios increase with altitudes in the lower stratosphere. Thus, air with large mixing ratios of ozone is transported downwards into the lower stratosphere, the region where chemical ozone destruction occurs. Ozone variations due to transport are often of the same magnitude as those due to chemical ozone destruction (e.g. Manney et al., 1994; von der Gathen et al., 1995; Müller et al., 1996; Rex et al., 2003a). Therefore, it is necessary to separate these two processes in order to quantify the chemical ozone loss in the stratosphere.

Different approaches have been developed over the past decade to separate transport and chemistry employing the explicit model calculation of diabatic descent (e.g. Rex et al., 1999b; Manney et al., 2003a; Knudsen et al., 1998; Goutail 
et al., 1999; Lefèvre et al., 1998; Harris et al., 2002). Another possibility of deriving chemical ozone loss is to exclude transport processes implicitly by the tracer-tracer correlation method (e.g. Proffitt et al., 1990; Müller et al., 1996, 1999, 2002; Tilmes et al., 2003b), as is used in this study.

Chemical ozone loss in the polar stratosphere is caused beyond doubt by the burden of CFCs in the atmosphere, which is due to anthropogenic emissions (e.g. Solomon, 1999; WMO, 2003). The inactive chlorine reservoir species are converted into an active - ozone-destroying - form through heterogeneous reactions on the surface of polar stratospheric clouds (PSCs). PSCs form during a cold period of the Arctic winter. Therefore, chemical ozone depletion is linked to meteorological conditions (e.g. Manney et al., 2003a; Rex et al., 2004). Santee et al. (2003) discussed the connection between interannual variability of the $\mathrm{ClO}$ abundance and meteorological conditions during the 1990s. The strongest $\mathrm{ClO}$ abundance was found in the very cold winter of 19951996 in the Arctic lower stratosphere.

In this paper, ozone loss was analysed consistently over the period of the last twelve years (1991-1992 to 2002-2003) using the tracer-tracer correlation method, mainly on the basis of Version 19 HALOE satellite observations (Russell et al., 1993). Recent improvements to the method (Müller et al., 2002; Tilmes et al., 2003b) and further enhancements, described in this study, allow a comprehensive error analysis of the derived chemical ozone loss. We present a detailed analysis for each year including the correlation between ozone loss, chlorine activation and the volume of possible PSC existence $\left(\mathrm{V}_{\mathrm{PSC}}\right)$.

A comparison is made between ozone loss derived using the tracer-tracer correlation method and other methods using model simulations to estimate transport processes. Reliable results within the range of uncertainty during a period of twelve years allow us to consider the correlation between $\mathrm{V}_{\text {PSC }}$ and the calculated column ozone loss and accumulated local ozone loss between early winter and spring. The correlation indicates an increase of ozone loss with increasing $\mathrm{V}_{\text {PSC }}$. This relation is not a linear correlation if the same time interval of ozone loss calculations and $\mathrm{V}_{\mathrm{PSC}}$ averaging is considered. Besides $\mathrm{V}_{\mathrm{PSC}}$, here further dependences of the chemical ozone loss were found. Other factors control chemical ozone loss. The illumination time of solar radiation onto cold parts of the vortex may have significant influence on ozone loss, as well as the loading of volcanic sulfate aerosols in the atmosphere.

\section{The tracer-tracer correlation technique}

\subsection{Methodology}

The TRAcer-tracer Correlation technique (referred to as "TRAC technique" in the following) has its origins in the study by Roach (1962) and later Allam et al. (1981). They first noticed that a relation between two different species arises through the elimination of dynamical variability from measurements in the atmosphere. Compact relations between long-lived tracers in the stratosphere were first observed by Ehhalt et al. (1983) and were simulated using various chemical transport models (Mahlman et al., 1986; Holton, 1986; Plumb and Ko, 1992; Avallone and Prather, 1997) and recently by Sankey and Shepherd (2003). Proffitt et al. (1990) first developed the TRAC technique to quantify chemical ozone loss inside an isolated vortex from high altitude aircraft measurements. Later this technique was applied and extended to satellite (Müller et al., 1996, 1997; Tilmes et al., 2003b) and balloon (Müller et al., 2001; Salawitch et al., 2002) measurements. The TRAC method was further used to investigate chlorine activation (through the analysis of HCl-tracer correlations) (e.g. Müller et al., 1996; Tilmes et al., 2003a) and denitrification (through the analysis of $\mathrm{NO}_{\mathrm{y}}-\mathrm{N}_{2} \mathrm{O}$ correlations) (e.g. Fahey et al., 1996; Rex et al., 1999a).

Over the course of the winter, constant compact relationships are expected for tracers with sufficiently long lifetimes for the air mass inside a polar vortex that is largely isolated from the surrounding air masses (Plumb and Ko, 1992). Therefore, advection in the polar vortex, in particular diabatic decent, cannot alter the relation between two chemically long-lived tracers (e.g. Proffitt et al., 1992; Proffitt et al., 1993). If one of the tracers is subject to chemical or physical change (active tracer), owing to the particular meteorological conditions inside the polar vortex, changes in mixing ratio are identified as changes of the tracer-tracer correlation (e.g. Proffitt et al., 1992; Müller et al., 1996, 2002; Tilmes et al., 2003b).

Here, we use the TRAC method to consider the correlation of two long-lived tracers inside the polar vortex during twelve Arctic winter periods. To decide whether profiles are inside or outside the Arctic vortex a methodology is employed based on UKMO meteorological analyses allowing accurate selection criteria (Tilmes et al., 2003b). Three vortex regions are defined, based on the algorithm derived by Nash et al. (1996), the vortex core, the outer vortex (the area between vortex core and vortex edge) and the outer part of the vortex boundary region (outside the vortex edge). Further, trajectory calculations were used to reposition each measured profile to noon. This is the time at which UKMO meteorological analyses are available to apply the Nash et al. (1996) algorithm .

The HALOE instrument (Russell et al., 1993) measures two long-lived tracers, namely $\mathrm{CH}_{4}$ and HF. Both tracers can be used individually to calculate chemical ozone loss with the TRAC technique because their lifetimes are sufficiently long (Müller et al., 2002; Tilmes et al., 2003b). Additionally, the use of these two long-lived tracers enables a further improved selection criterion for the HALOE profiles. Because $\mathrm{CH}_{4}$ and HF have very long lifetimes, the relationship between $\mathrm{CH}_{4}$ and $\mathrm{HF}$ inside the polar vortex region is nearly linear 
Table 1. $\mathrm{CH}_{4} / \mathrm{HF}$ reference relations from HALOE observations inside the vortex core: 1991-1992 to 2002-2003. Polynomial functions of the form: $[y]=\sum_{i=0}^{n} a_{i} \cdot[x]^{i}$ with $n \leq 4$ are shown as well as the standard deviation of the observation points from the fitted reference function $\sigma$.

\begin{tabular}{|c|c|c|c|c|c|c|}
\hline valid $[x]$ & $a_{0}$ & $a_{1}$ & $a_{2}$ & $a_{3}$ & $a_{4}$ & $\sigma$ \\
\hline 1991-1992 & & & & & & \\
\hline $\begin{array}{l}0.1-1.1 \\
\mathbf{1 9 9 2 - 1 9 9 3}\end{array}$ & 1.83 & -2.49 & 2.72 & -3.31 & 1.63 & $9.03 \times 10^{-2}$ \\
\hline $\begin{array}{l}0.1-1.3 \\
\mathbf{1 9 9 3 - 1 9 9 4}\end{array}$ & 1.64 & -1.71 & $7.33 \times 10^{-1}$ & $-1.91 \times 10^{-2}$ & $-1.55 \times 10^{-1}$ & $9.95 \times 10^{-2}$ \\
\hline $\begin{array}{l}0.1-1.35 \\
\mathbf{1 9 9 4 - 1 9 9 5}\end{array}$ & 1.85 & -2.75 & 3.70 & -3.15 & $9.31 \times 10^{-1}$ & $1.04 \times 10^{-1}$ \\
\hline $\begin{array}{l}0.1-1.4 \\
\mathbf{1 9 9 5}-\mathbf{1 9 9 6}\end{array}$ & 1.76 & -2.71 & 4.18 & -3.71 & 1.10 & $8.98 \times 10^{-2}$ \\
\hline $\begin{array}{l}0.1-1.5 \\
1996-1997\end{array}$ & 1.65 & -1.16 & $1.77 \times 10^{-1}$ & $-3.63 \times 10^{-2}$ & & $8.11 \times 10^{-2}$ \\
\hline $\begin{array}{l}0.1-1.5 \\
1997-1998\end{array}$ & 1.76 & -1.88 & 2.25 & -2.00 & $5.87 \times 10^{-1}$ & $7.92 \times 10^{-2}$ \\
\hline $\begin{array}{l}0.1-1.55 \\
\mathbf{1 9 9 8}-\mathbf{1 9 9 9}\end{array}$ & 1.71 & -1.47 & $8.75 \times 10^{-1}$ & $-4.91 \times 10^{-1}$ & $8.44 \times 10^{-2}$ & $8.14 \times 10^{-2}$ \\
\hline $\begin{array}{l}0.2-1.6 \\
\mathbf{1 9 9 9 - 2 0 0 0}\end{array}$ & 1.98 & -3.44 & 4.84 & -3.40 & $8.07 \times 10^{-1}$ & $8.46 \times 10^{-2}$ \\
\hline $\begin{array}{l}0.1-1.65 \\
\mathbf{2 0 0 0 - 2 0 0 1}\end{array}$ & 1.72 & -1.89 & 1.53 & $-8.55 \times 10^{-1}$ & $1.73 \times 10^{-1}$ & $8.67 \times 10^{-2}$ \\
\hline $\begin{array}{l}0.1-1.7 \\
\mathbf{2 0 0 1 - 2 0 0 2}\end{array}$ & 2.05 & -2.99 & 4.10 & -3.05 & $7.54 \times 10^{-1}$ & $7.27 \times 10^{-2}$ \\
\hline $\begin{array}{l}0.1-1.6 \\
\mathbf{2 0 0 2}-\mathbf{2 0 0 3}\end{array}$ & 1.89 & -2.54 & 2.90 & -1.93 & $4.40 \times 10^{-1}$ & $7.39 \times 10^{-2}$ \\
\hline $0.1-1.6$ & 1.91 & -2.93 & 3.90 & -2.66 & 0.61 & $8.75 \times 10^{-2}$ \\
\hline
\end{tabular}

and does not change significantly over the whole lifetime of the vortex in each year. In this study, a linear relationship of HALOE measurements was derived from profiles inside the polar vortex for each year, with a standard deviation of less than $0.1 \mathrm{ppmv}$ (Table 1). Profiles deviating by more than 0.2 ppmv from the constant $\mathrm{CH}_{4} / \mathrm{HF}$ relation are neglected in order to eliminate observations that are uncertain.

Besides $\mathrm{CH}_{4}$ and HF, the HALOE instrument measures ozone and $\mathrm{HCl}$, which are used as the active tracers in this study. $\mathrm{HCl}$ is chemically destroyed by heterogeneous reactions and increases due to the deactivation of chlorine via the reaction of $\mathrm{Cl}$ with $\mathrm{CH}_{4}$. Chemical ozone loss occurs if large concentrations of chemically active halogen compounds are present in an air mass. This is the case in most years in late winter and spring inside the polar vortex in the presence of sunlight.

To derive chemical losses of ozone, first the ozone-tracer relation has to be determined at a time before ozone has chemically changed. This is usually the case in the early winter when rather little sunlight is present. The ozonetracer relation, referred to as "early winter reference function", is mathematically formulated as a polynomial and is considered as the reference for chemically unperturbed con- ditions. It is necessary to derive an early winter reference function for each of the twelve years considered to determine chemical ozone loss for each year. The observation time of the underlying profiles considered has to be chosen carefully for this purpose. The turning point from summer to winter circulation marks the time of the formation of the polar vortex. Thus, the time of the minimum of the ozone column density is the earliest time at which the early winter reference function can be determined. This point in time can be derived considering the total ozone column from global satellite measurements. Tilmes (2003, Sect. 3.3) used TOMS observations for this purpose. On the other hand, this time of the winter may not be the most suitable time to derive the early winter reference function if the early vortex is not yet strong enough. Horizontal mixing across the vortex edge may change the tracer-tracer relation without chemical changes. A case in point is the winter 1996-1997, where the ozone-tracer relation changed until the beginning of January 1997, due to horizontal mixing processes (Tilmes et al., 2003b). Further, in winter 1991-1992 the ozone-tracer relation changed from November 1991 to December 1991 due to mixing (see Sect. 3.1). 
In summary, the early winter reference function has to be determined at a time when the vortex has already formed and, additionally, is sufficiently isolated from mid-latitude air, but at the same time early enough so that no ozone loss has yet taken place. Therefore, if the vortex is isolated, the reference function has to be derived as early as possible, if observations are available. These conditions are generally fulfilled for each of the derived reference functions and some exceptions will be discussed in detail below.

To draw conclusions on possible chlorine activation and therefore possible ozone loss in a certain time period, the consideration of the value of "volume of possible PSC existence", $\mathrm{V}_{\mathrm{PSC}}$, is useful because significant chlorine activation is not possible without the existence of PSCs (e.g. Solomon, 1999). Additionally, here, the amount of solar illumination on the cold parts of the polar vortex is considered. Significant ozone loss is not possible without the existence of active chlorine components and further, without the presence of sunlight (e.g. Solomon, 1999).

$\mathrm{V}_{\mathrm{PSC}}$ describes the total volume on a certain potential temperature level, where the temperature (here determined from the UKMO analysis) does not exceed the PSC threshold temperature. This PSC threshold temperature was calculated (Hanson and Mauersberger, 1988) for a $\mathrm{HNO}_{3}$ mixing ratio of $10 \mathrm{ppbv}$ and a $\mathrm{H}_{2} \mathrm{O}$ mixing ratio of $5 \mathrm{ppmv}$. Therefore, if PSC existence is not possible at the time before the early winter reference function was derived, no chlorine activation and thus no ozone loss should have occurred. On the other hand, an existing potential for PSCs during the early winter may result in active chlorine components that cause ozone loss if sunlight is present (see below). Using $V_{\text {PSC }}$ as an indicator for chlorine activation, one has to keep in mind that these calculations of $\mathrm{V}_{\mathrm{PSC}}$ do not include PSCs which occur on the mesoscale due to orographically induced mountain waves (e.g. Fueglistaler et al., 2003). Further, the use of different meteorological analyses may result in differences up to $\approx 25 \%$ of temperature analyses (Knudsen et al., 2002; Manney et al., 2003a) and therefore in differences in the calculated $\mathrm{V}_{\text {PSC. }}$. If HALOE measurements are available at the time for which the early winter reference function is determined, chlorine activation can be clearly detected from the TRAC analysis of HCl-tracer correlations (Müller et al., 1996; Tilmes et al., 2003a) as a strong loss of $\mathrm{HCl}$.

HALOE makes measurements fifteen times per day at each sunrise and sunset occultation along two latitude lines. These lines move between $80^{\circ} \mathrm{N}$ and $80^{\circ} \mathrm{S}$ in about 45 days. Therefore, measurements in high northern latitudes are available every two or three months, depending on the year and in most of the years considered relatively few observations were available inside the early vortex. Thus, to derive the early winter reference function, additional data sources such as ILAS satellite measurements and balloon measurements were used.

For two out of twelve winters, for which no direct measurements could be obtained in the early vortex, a methodol- ogy has been developed to estimate the early winter reference functions. In this way, for each of the twelve winters considered a reliable early winter $\mathrm{O}_{3}$-tracer reference function could be derived, as described below in Sect. 3 .

A reliable calculation of ozone loss during the course of the winter is possible, as long as the polar vortex is isolated well enough so that the tracer-tracer correlation remains compact and unaltered in the absence of chemical changes. Tilmes et al. (2003b) and Tilmes (2003) have shown that a compact ozone-tracer correlation exists inside the polar vortex during January in the Arctic winter 1996-1997 when no chemical ozone loss is expected due to the lack of sunlight based on ILAS observations. The ILAS instrument measured seven months in high northern latitudes $\left(58^{\circ} \mathrm{N}-73^{\circ} \mathrm{N}\right)$, thus providing good coverage of the polar vortex over this time period. Moreover, it was shown that the vortex has to be isolated well enough to obtain a compact reliable reference correlation. In the winter 1996-1997 this situation was found for the Arctic vortex since early January 1997. Further, during winter and spring an exact criterion has to be defined to decide whether profiles are measured in or outside the vortex, because the characteristics of air outside the vortex are very different to vortex air. Using a mixture of profiles measured in and outside the vortex will lead to the erroneous conclusion that a compact ozone-tracer correlation does not exist.

Khosrawi et al. (2004) discussed the evolution of $\mathrm{O}_{3} / \mathrm{N}_{2} \mathrm{O}$ of different isentropic levels based on ILAS measurements 1996-97. They did not separate isentropic levels at different altitudes into measurements inside and outside the vortex and therefore did not obtain a compact January relationship, whereas exactly the same data indicate a compact $\mathrm{O}_{3} / \mathrm{N}_{2} \mathrm{O}$ correlation inside the vortex core if sorted according to the vortex criterion used here (Tilmes, 2003) (Fig. 4.4, the poleward edge of the vortex boundary region, using the algorithm derived by Nash et al., 1996).

In the study by Sankey and Shepherd (2003), the $\mathrm{O}_{3} / \mathrm{CH}_{4}$ correlation is considered in the course of an Arctic winter analysing results of the CMAM model. The ozone-tracer correlations from the model on the different isentropic levels are similar to those derived by Khosrawi et al. (2004) based on ILAS observations. Thus the shape of the lines should not be seen as a lack of compactness inside the polar vortex, as it is interpreted by Sankey and Shepherd (2003), but it is rather the result of considering measurements in high northern latitudes, which are not separated into profiles measured outside and inside the polar vortex.

Further, Müller et al. (2001) used balloon-borne measurements in the Arctic winter 1991-1992 to show that the impact of mixing between air masses from outside the vortex with air inside the vortex would result in a tendency to greater ozone mixing ratios in the ozone-tracer relation. Recent model calculations for the development of tracer distributions in the winter 1999/2000 (Konopka et al., 2003) corroborate this finding. The effect should thus lead to an underestimation of the chemical ozone loss. Tilmes et al. (2003b), 
using ILAS observations for winter 1996-1997, have shown that this effect is not significant after early January 1997. Even inside the vortex remnants in May 1997, a compact correlation is found.

In this study we argue that a compact correlation exists during all the observed twelve Arctic winters. Especially, the analysis of the very warm winters (1998-1999 and 20012002) - where no substantial chemical ozone loss is expected - demonstrates that the ozone-tracer correlations do not significantly change due to mixing processes, although the vortices are less strong compared to other winters. Only if the vortex completely breaks down and reforms, as was the case in March 2001, is it impossible to obtain reliable results using the TRAC technique.

\subsection{Error analysis}

An error analysis was performed consistently for all the years analysed here. In the early winter and during the course of the winter, the scatter of the ozone-tracer relations arises, on the one hand, due to variability of the mixing ratios of tracers inside the vortex, and, on the other hand, it may possibly be due to the random error of the satellite measurements. Both these uncertainties are estimated by calculating the standard deviation of the profiles contributing to the early winter reference function.

Further, no systematic error of the satellite measurements is taken into account because assuming that all available measurements of one satellite are affected in the same way it would have no impact on the ozone loss calculation. Therefore, the uncertainty of results was derived from the uncertainty of the early winter reference function. Additionally, the standard deviation of monthly averaged column ozone loss deduced from the individual profiles is considered. This describes the homogeneity of the deduced ozone loss during a particular time span and in a particular region. Inhomogeneities may be caused by both the inhomogeneity of the ozone loss inside the vortex and the random error of the satellite measurements, as described above.

Mixing processes may change the early winter reference function without chemical change if the vortex is not isolated. However, a significant increase in the uncertainty range due to mixing processes in the early vortex is not expected, because each profile used to derive an early winter reference function was located poleward of the vortex edge (using the Nash criterion). The vortex was isolated for most years considered at the time when the reference function was derived. This can be assumed regarding the evolution of calculated PV values at the vortex edge using the Nash criterion. At the time when the reference function was derived, PV values at the vortex edge are 30-35 PV units $\left(1 \mathrm{PVU}=10^{-6} \mathrm{~K} \mathrm{~m}^{2} /(\mathrm{kg} \mathrm{s})\right)$ at the $475 \mathrm{~K}$ level for all year. In the following two weeks, PV values increase in the most of the years at the $475 \mathrm{~K}$ level (except for the winter 19981999). Therefore, the uncertainty due to dynamics on the reference function should be small in all the years considered. In 1998-1999 the vortex was less strong although still isolated; in this winter, a stronger influence of mixing on the early vortex reference cannot be excluded.

The impact of mixing processes during the entire winter period of the years considered should be small for the same reason. Only in the middle of February 2001 did the vortex break down completely. Therefore, no ozone loss is calculated after this event. In 1991-1992, a major warming at the end of January may have impacted the tracer-tracer correlations leading to an underestimation of chemical ozone loss in this year (see Sect. 2.1). Therefore, the derived value of ozone loss for this winter constitutes a lower limit. Further, results of the winter 1997-1998 and 2000-2001 had to be derived using a reference function based on climatology values and are thus more uncertain compared to results derived from a reference function based directly on measurements of the specific year. Nevertheless, these reference functions are the average of all the de-trended early winter reference functions and should therefore be reliable within the reported range of uncertainty.

To derive results with minimum uncertainty, it is also necessary to calculate ozone loss in the appropriate altitude range. Column ozone loss is therefore calculated for an altitude range of $380-550 \mathrm{~K}, 400-500 \mathrm{~K}$ and $40-100 \mathrm{hPa}$ (to compare the results with other studies) from HALOE observations, because within this range the empirical ozone-tracer reference relations are valid and possible mixing processes below $380 \mathrm{~K}$ are excluded. The smallest uncertainty arises if the column ozone loss is calculated in an altitude range between $400-500 \mathrm{~K}$. Here, the vortex is most compact and accuracies of satellite data are better than at lower altitudes.

\section{Impact of meteorological conditions on ozone-tracer and $\mathrm{HCl}$-tracer relations}

\subsection{Development of early winter reference functions}

The early winter reference function is derived individually from all available HALOE measurements inside the early vortex for the six winters $1992-1993$ to $1995-1996$ and in 1998-1999 and 2001-2002. The profiles used were located inside the early vortex for each year, at a time when in general no ozone loss was expected (as outlined below). For 19911992 (Müller et al., 2001), 1999-2000 (Müller et al., 2002) and 2002-2003 (Tilmes et al., 2003a), early winter reference functions were derived from balloon observations. In winter 1996-1997, ILAS observations were used to define an early winter reference function to calculate ozone loss from measurements made by HALOE in late winter and spring (Tilmes et al., 2003b).

An overview of the mathematically formulated tracertracer early winter reference functions derived only from HALOE observations inside the early vortex is summarised 
Table 2. $\mathrm{O}_{3} / \mathrm{HF}$ reference relations from HALOE observations: 1992-1993 to 2001-2002 (see text). Polynomial functions of the form: $[y]=\sum_{i=0}^{n} a_{i} \cdot[x]^{i}$ with $n \leq 4$ are shown as well as the standard deviation of the observation points from the fitted reference function $\sigma$.

\begin{tabular}{lllllll}
\hline valid $[x]$ & $a_{0}$ & $a_{1}$ & $a_{2}$ & $a_{3}$ & $a_{4}$ & $\sigma$ \\
\hline $\mathbf{1 9 9 2 - 1 9 9 3}$ & & & & & & \\
$0.01-1$. & $-199.82 \times 10^{-2}$ & 5.93 & $1.47 \times 10^{1}$ & $-3.19 \times 10^{1}$ & $1.55 \times 10^{1}$ & $3.46 \times 10^{-1}$ \\
$\mathbf{1 9 9 3 - 1 9 9 4}$ & & & & & & \\
$0.01-1.1$ & $2.60 \times 10^{-1}$ & 3.81 & 8.16 & $-1.27 \times 10^{1}$ & 4.42 & $2.49 \times 10^{-1}$ \\
$\mathbf{1 9 9 4 - 1 9 9 5}$ & & & & & & \\
$0.01-1.1$ & $-1.03 \times 10^{-1}$ & 5.80 & $-3.04 \times 10^{-1}$ & -1.73 & $4.79 \times 10^{-3}$ & $3.77 \times 10^{-1}$ \\
$\mathbf{1 9 9 5 - 1 9 9 6}$ & & & & & & \\
$0.01-1.0$ & $-1.70 \times 10^{-1}$ & 7.93 & -6.08 & 1.92 & & $1.24 \times 10^{-1}$ \\
$\mathbf{1 9 9 7 - 1 9 9 8}$ & & & & & & \\
$0 .-1.3$ & $3.66 \times 10^{-2}$ & 5.87 & 5.91 & $-1.35 \times 10^{1}$ & 5.37 & $2.89 \times 10^{-1}$ \\
$\mathbf{1 9 9 8 - 1 9 9 9}$ & & & & & & \\
$0.01-1.2$ & $3.30 \times 10^{-1}$ & 3.23 & $1.10 \times 10^{1}$ & $-1.74 \times 10^{1}$ & 6.91 & $1.86 \times 10^{-1}$ \\
$\mathbf{2 0 0 0 - 2 0 0 1}$ & & & & & & \\
$0 .-1.3$ & $7.27 \times 10^{-3}$ & $1.36 \times 10^{-1}$ & $1.50 \times 10^{1}$ & $-1.60 \times 10^{1}$ & 4.66 & $3.02 \times 10^{-1}$ \\
$\mathbf{2 0 0 1 - 2 0 0 2}$ & & & & & $-7.06 \times 10^{-1}$ & $1.48 \times 10^{-1}$ \\
\hline $0.1-1.5$ & $-4.83 \times 10^{-1}$ & $1.03 \times 10^{1}$ & $-1.09 \times 10^{1}$ & 4.98 & & \\
\hline
\end{tabular}

Table 3. $\mathrm{O}_{3} / \mathrm{CH}_{4}$ reference relations from HALOE observations: 1992-1993 to 2001-2002 (see text). Polynomial functions of the form: $[y]=\sum_{i=0}^{n} a_{i} \cdot[x]^{i}$ with $n \leq 4$ are shown as well as the standard deviation of the observation points from the fitted reference function $\sigma$.

\begin{tabular}{lllllll}
\hline valid $[x]$ & $a_{0}$ & $a_{1}$ & $a_{2}$ & $a_{3}$ & $a_{4}$ & $\sigma$ \\
\hline $\mathbf{1 9 9 2 - 1 9 9 3}$ & & & & & & \\
$0.45-1.65$ & 8.77 & $-2.39 \times 10^{1}$ & $4.51 \times 10^{1}$ & $-3.59 \times 10^{1}$ & 9.34 & $2.31 \times 10^{-1}$ \\
$\mathbf{1 9 9 3 - 1 9 9 4}$ & & & & & & \\
$0.4-1.7$ & 4.72 & -6.55 & $1.73 \times 10^{1}$ & $-1.75 \times 10^{1}$ & 5.12 & $3.09 \times 10^{-1}$ \\
$\mathbf{1 9 9 4 - 1 9 9 5}$ & & & & & & \\
$0.45-1.6$ & 4.19 & -3.51 & $1.14 \times 10^{1}$ & $-1.38 \times 10^{1}$ & 4.44 & $3.56 \times 10^{-1}$ \\
$\mathbf{1 9 9 5 - 1 9 9 6}$ & & & & & & \\
$0.6-1.7$ & -2.98 & $2.55 \times 10^{1}$ & $-3.00 \times 10^{1}$ & $1.24 \times 10^{1}$ & -1.68 & $3.09 \times 10^{-1}$ \\
$\mathbf{1 9 9 7 - 1 9 9 8}$ & & & & & & \\
$0.6-1.7$ & 3.70 & -2.09 & $1.00 \times 10^{1}$ & $-1.19 \times 10^{1}$ & 3.55 & $4.40 \times 10^{-1}$ \\
$\mathbf{1 9 9 8 - 1 9 9 9}$ & & & & & & $1.04524 \times 10^{-1}$ \\
$0.6-1.7$ & $4.55 \times 10^{-1}$ & $1.27 \times 10^{1}$ & $-1.27 \times 10^{1}$ & 3.11 & & \\
$\mathbf{2 0 0 0 - 2 0 0 1}$ & & & & & & \\
$0.6-1.7$ & 5.00 & -8.95 & $2.14 \times 10^{1}$ & $-1.92 \times 10^{1}$ & 5.16 & $4.43 \times 10^{-1}$ \\
$\mathbf{2 0 0 1 - 2 0 0 2}$ & & & & & & \\
$0.6-1.7$ & 4.49 & -6.35 & $1.36 \times 10^{1}$ & $-1.26 \times 10^{1}$ & 3.55 & $1.85 \times 10^{-1}$ \\
\hline
\end{tabular}

in Tables 2 and 3. As in Table 1, polynomial functions of the form: $[y]=\sum_{i=0}^{n} a_{i} \cdot[x]^{i}$ with $n \leq 4$ are reported as well as the standard deviation $\sigma$ of the observation points from the fitted reference function. The empirical relations are valid for mixing ratios of $\mathrm{CH}_{4}$ in ppmv, $\mathrm{HF}$ in ppbv and $\mathrm{O}_{3}$ in ppmv, respectively.

The time (interval) at which the early winter reference functions were derive in each year is shown in Fig. 1 by vertical black lines. In 1998-1999 and 2000-2001, the HALOE climatology was used to derive the early winter reference function. Therefore, the time interval between the earliest date of all profiles used and latest date of all profiles used in these years is shown. This figure shows daily sun hours at possible PSC areas for all the twelve years considered. It indicates, on the one hand, wether PSC existence is possible at the time when the early winter reference function was derived and, further, how strongly these PSC areas were illuminated before the early winter reference function was 

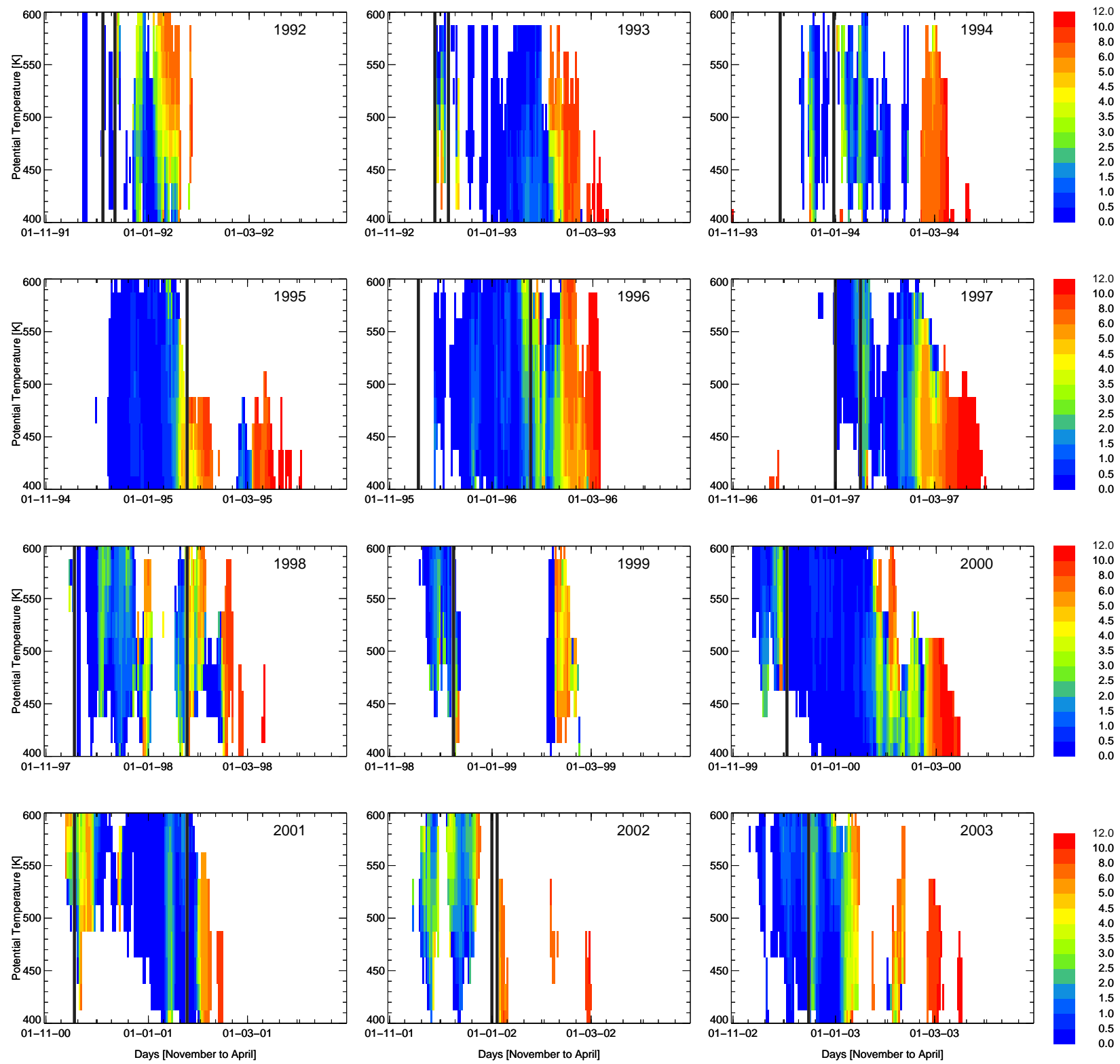

Fig. 1. Daily sun hours at possible PSC areas over the entire polar vortex, as a function of altitude, are shown for the period from November to April for the twelve winters between 1991-92 and 2002-2003. White area indicates regions where the area of possible PSC existence is zero. Black lines indicate the time (interval) for which the early winter reference function was derived.

calculated. In this way, we can estimate if some ozone loss may have occurred before the early winter reference function was derived, because the existence of PSCs and solar radiation are responsible for ozone loss.

As an example, the derivation of the early winter reference function in 1995-1996 from HALOE profiles inside the early vortex is discussed. In this winter, HALOE vortex profiles were available at the end of November. At this time of the winter, the $\mathrm{V}_{\text {PSC }}$ was negligible. No deviation from the unperturbed $\mathrm{HCl} / \mathrm{HF}$ relation was found. Therefore, no activated chlorine compounds and thus no ozone loss can be expected. Two months later, at the end of January (Fig. 2, bottom panel), one profile inside the vortex boundary region indicates strong chlorine activation noticeable as a change in the $\mathrm{HCl} / \mathrm{HF}$ relation corresponding to a large $\mathrm{V}_{\mathrm{PSC}}$ during January. But still no changes in the $\mathrm{O}_{3} / \mathrm{HF}$ relation are detected (Fig. 2, top panel). Changes in the $\mathrm{O}_{3} / \mathrm{HF}$ relation due to isentropic mixing are not expected during December and January, because at that time the vortex was already very strong. Further, at this time and location $\left(\approx 50^{\circ} \mathrm{N}\right)$ of the profile solar illumination is expected, but the vortex was illuminated only for a very short time before 23-31 January 

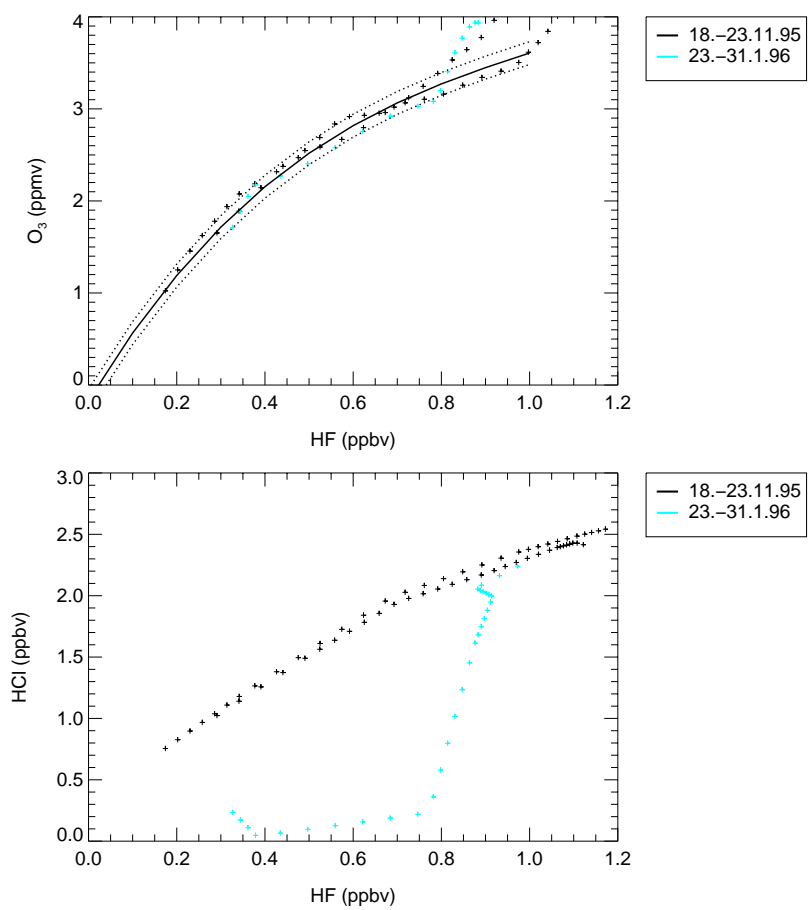

Fig. 2. Tracer-tracer profiles inside the outer early vortex of the year 1995-1996 from HALOE measurements with HF as the passive tracer. In the top panel, the chemical active tracer is $\mathrm{O}_{3}$ and in the bottom panel the chemical active tracer is $\mathrm{HCl}$. The early winter reference function for the $\mathrm{O}_{3} / \mathrm{HF}$ relation 1995-1996, top panel, is indicated as a black solid line and the uncertainty of the reference function is represented by black dotted lines.

1996 (see Fig. 1). Therefore, the $\mathrm{HCl}$ was already strongly reduced although little ozone loss inside the range of uncertainty of the reference function was found. Of course, the $\mathrm{HCl}$-tracer relation changes much faster than the $\mathrm{O}_{3}$-tracer relation, because chlorine activation occurs on much shorter time scales than ozone loss. The fact that in 1996 - in spite of the early vortex having been cold and strong - no significant ozone loss occurred during January may be explained by the very small amount of sunlight that illuminated the early vortex.

In the following, the derivation of the early winter reference function from balloon observations in 1991-1992, 1999-2000 and 2002-2003 is briefly described. Thereafter, early winter reference functions of the other years considered are discussed. For winter 1991-1992, the early winter reference function was derived from measurements of ozone and $\mathrm{N}_{2} \mathrm{O}$ made by cryosampler measurements (Schmidt et al., 1987) on 5 and 12 December 1991, respectively. At this time, a small $\mathrm{V}_{\mathrm{PSC}}$ was calculated, but these $\mathrm{V}_{\text {PSC }}$ are not illuminated (see Fig. 1) and therefore no ozone loss can be expected before this time.

The $\mathrm{O}_{3} / \mathrm{N}_{2} \mathrm{O}$ profiles were transformed to $\mathrm{O}_{3} / \mathrm{CH}_{4}$ with the $\mathrm{N}_{2} \mathrm{O} / \mathrm{CH}_{4}$ relationship from Engel et al. (1996), see Müller

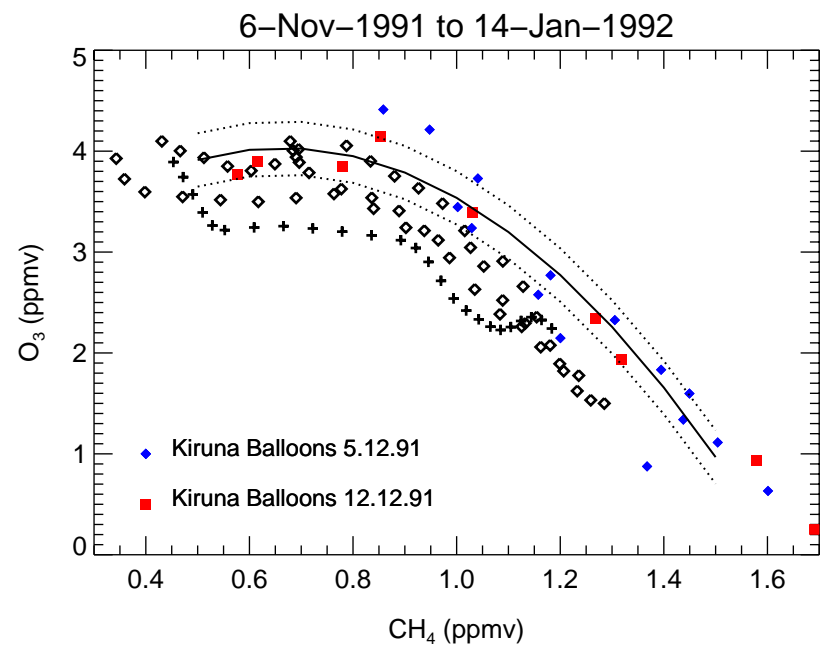

Fig. 3. The early winter reference function 1991-1992, shown as a black line, was derived from balloon measurements from December 1991 (coloured symbols). Dotted lines indicate the range of uncertainty in the reference function. Observations made by HALOE within the vortex in November 1991 (black plus signs) and in January (black squares) are also shown.

et al. (2001). To derive the $\mathrm{O}_{3} / \mathrm{HF}$ reference function, the $\mathrm{O}_{3} / \mathrm{CH}_{4}$ relation was converted using the $\mathrm{CH}_{4} / \mathrm{HF}$ relation derived from HALOE observations for the winter 1991-1992 (Table 1).

The vortex started forming in November 1991. One HALOE profile was found inside the early vortex at the beginning of November, with low ozone mixing ratios compared to profiles inside the vortex measured in January (see Fig. 3, black plus signs). At that time the vortex was not well developed and mixing in of air masses from outside the vortex was still possible. Therefore, the low ozone mixing ratios observed in November increased until the vortex became fully isolated in December. The HALOE profiles in January 1992 scatter below the derived reference relation by about 1.2 ppmv $\mathrm{CH}_{4}$ level (see Fig. 3). Thus ozone loss had already occurred during January 1992, in accordance with a relatively small, but illuminated volume of possible PSC existence in the first two weeks of January (see Figs. 1 and 8). In contrast to the winter 1995-1996, ozone loss during January 1992 was much stronger although $\mathrm{V}_{\text {PSC }}$ in January 1996 was even larger than in January 1991-1992. However, $\mathrm{V}_{\text {PSC }}$ were much less illuminated in January 1996 compared to January 1992 (see Fig. 1). This shows that ozone loss is influenced by solar radiation in addition to $\mathrm{V}_{\mathrm{PSC}}$, as further discussed in Sect. 6.

In winter 1999-2000, again no HALOE observations were available inside the early vortex to derive the early winter reference function. Fortunately, during the SOLVE-THESEO 2000 campaign two balloon flights have been conducted inside the early vortex, the OMS (Observations of the Middle 

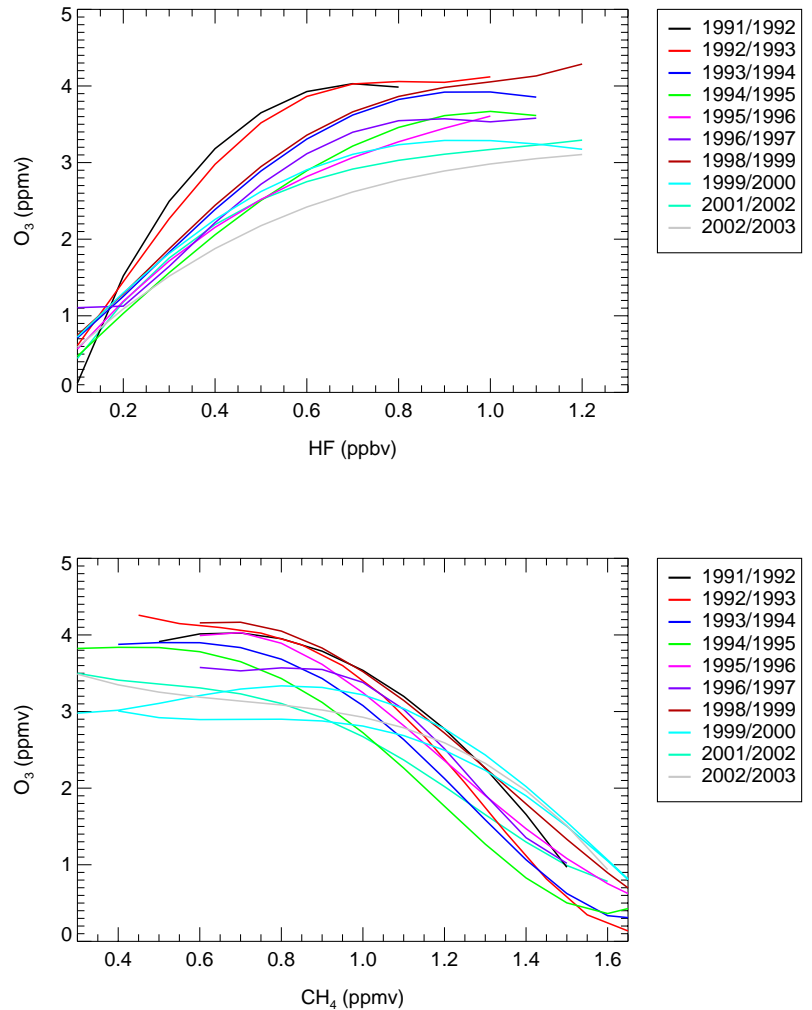

Fig. 4. Early winter reference relations for the ten years from 19911992 to 2002-2003 are indicated as coloured lines. $\mathrm{O}_{3} / \mathrm{HF}$ is shown in the top panel and $\mathrm{O}_{3} / \mathrm{CH}_{4}$ is shown in the bottom panel.

Stratosphere) in-situ flight on 19 November 1999 and the OMS remote flight on 3 December 1999 (e.g. Müller et al., 2002). HF measurements were only available from the MkIV instrument on the OMS-remote flight. Thus, these data were used to derive the $\mathrm{O}_{3} / \mathrm{HF}$ reference function for this winter. Two early winter reference functions were derived using $\mathrm{CH}_{4}$ as the long-lived tracer, one was derived using the OMSin-situ measurements and the second using the OMS-remote flight measurements (Müller et al., 2002). Only a little ozone loss may have already occurred on 3 December 1999 because of small $\mathrm{V}_{\mathrm{PSC}}$ that is slightly illuminated (see Fig. 1).

For 2002-2003, MkIV balloon observations in midDecember 2002 (Toon et al., 1999) were used to derive the early winter reference function (Tilmes et al., 2003a). The early winter reference functions of the winters 2002-2003 were derived from measurements at a time when the vortex had already developed. Before this time, a large volume of PSCs had already been detected and some activation of chlorine had already occurred in altitudes above $500 \mathrm{~K}$ (Tilmes et al., 2003a). However, hardly any illumination of the PSC area was detected and no significant ozone loss can be expected before the time when the reference function was derived.

In winters 1992-1993, 1993-1994, 1995-1996 and 19961997, the early winter reference functions were derived in a

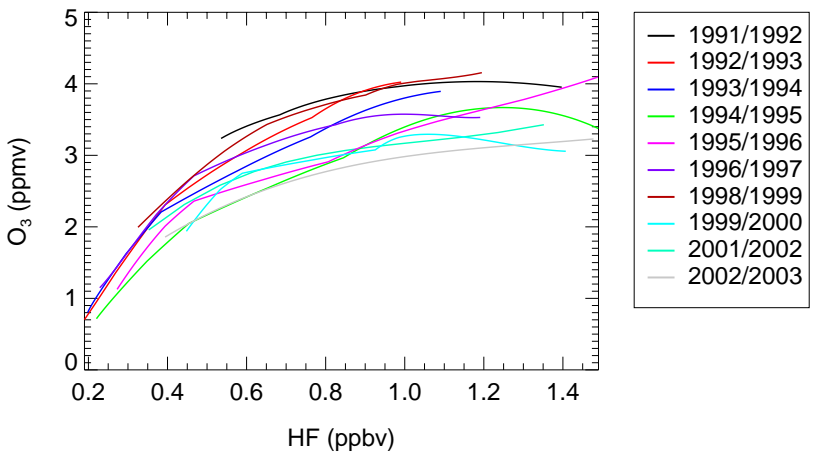

Fig. 5. Early winter reference relations for ten years from 19911992 to $2002-2003$ are indicated as coloured lines. $\mathrm{O}_{3} / \mathrm{HF}$ is shown; HF being corrected for the growth rate of HF derived from the HALOE $\mathrm{CH}_{4} / \mathrm{HF}$ relationship for each year (Tilmes, 2003).

certain time interval (see Fig. 1). At the beginning of this time interval, no ozone loss is expected because PSCs were detected (see Fig. 1). At the end of this time interval, the analysis does not show any ozone loss. However, only profiles inside the outer vortex are considered for most of this year to derive the early winter reference function, so we cannot prove wether ozone loss had already occurred inside the vortex core.

HALOE measurements in January 1994-1995 show strong deviations of the $\mathrm{HCl} / \mathrm{HF}$ relations at the time when the reference function was deduced. A strong volume of PSCs was calculated before that time, and some illumination of the PSCs was detected. Rex et al. (2003a) and Goutail et al. (1999) reported large ozone loss rates for January 1995. These losses may have already resulted in a small decrease of ozone in the $\mathrm{O}_{3} / \mathrm{HF}$ relation before the time when the reference function was deduced. Therefore, these ozone losses cannot be included in the calculations below. As in 1994 1995, in winter 2001-2002 some ozone loss may have occurred at the time when the reference function was derived. However, VPSC was much smaller in early 2001-2002. The derived ozone-tracer early winter reference functions for ten out of twelve years are shown in Fig. 4.

The deduced ozone-tracer relation in the early winter has its own characteristics each year. This is due to inter-annual differences in polar vortex development and not due to chemical loss (Manney et al., 2003b). Considering ozone-tracer relations, year by year variations are expected to be influenced by a trend of mixing ratios of the long-lived tracer used. This is the case using HF as the long-lived tracer (Fig. 4, top panel), because HF mixing ratios increased by $\approx 0.4$ ppbv in the middle stratosphere from 1991 to 2000 (Tilmes, 2003).

On the other hand, the growth rate of $60 \mathrm{ppbv}$ in 12 years of $\mathrm{CH}_{4}$ - taken from the tropospheric growth rate derived by Simpson et al. (2002) - is very small compared to the observed stratospheric $\mathrm{CH}_{4}$ mixing ratios (between 
$0.5-1.5 \mathrm{ppmv}$ ) and therefore is not significant for the present analysis. Further, ozone was relatively constant during the 1990s in northern mid-latitudes (WMO, 2003). Nevertheless, a decrease of ozone was found in the polar regions, but mainly in the southern hemisphere (WMO, 2003). Therefore, considering $\mathrm{O}_{3} / \mathrm{CH}_{4}$ reference functions (Fig. 4, bottom panel) the interannual differences of the early winter reference functions are not a result of a significant trend of methane. In this study, we obtain some indications of a trend of ozone in high northern altitudes towards lower ozone mixing ratios, but interannual differences in ozone mixing ratios are possible for different reasons (as described below). $\mathrm{O}_{3} / \mathrm{HF}$ early winter reference functions can be de-trended with regard to HF, using the HF growth rate deduced from the HALOE HF/CH 4 relationships (Table 1) (Tilmes, 2003).

The range of interannual differences of $\approx 1 \mathrm{ppmv}$ ozone mixing ratio - in altitudes above the $0.8 \mathrm{ppbv}$ level of $\mathrm{HF}$ or the 1.0 ppmv level of $\mathrm{CH}_{4}$ - are similar for both $\mathrm{O}_{3} / \mathrm{HF}$ and $\mathrm{O}_{3} / \mathrm{CH}_{4}$ relationships (see Figs. 4, bottom panel and 5). The largest ozone mixing ratios are found in winter 19911992. This is possibly due to enhanced global transport in this winter owing to the eruption of Pinatubo in June 1991. Very small ozone mixing ratios are found for the three winters 1999-2000, 2001-2002 and 2002-2003. This may be due to an earlier isolation of the polar vortex, for example in winter 2002-2003. Additionally, ozone loss may have already occurred at the time when the reference function was derived in winter 1999-2000 and 2001-2002 (see Fig. 1). Due to the different influences that control ozone mixing ratios in high northern latitudes in the early winter, a possible trend of ozone cannot be determined in this study.

Thus, it is not possible to use one single reference function for all years. For the winter 1997-1998 and 2000-2001, neither HALOE nor any other measurements were obtained in the early vortex. Therefore, the early winter reference functions of these years were constructed from a climatology of all HALOE profiles measured inside the early vortex over the ten year period between 1992 and 2002. Actually, measurements inside the early vortex are available for six winters (1992-1993, 1993-1994, 1994-1995, 1995-1996, 19981999 and 2001-2002). The HALOE $\mathrm{O}_{3} / \mathrm{HF}$ and $\mathrm{O}_{3} / \mathrm{CH}_{4}$ profiles are corrected for the growth rate of $\mathrm{HF}$ and $\mathrm{CH}_{4}$, respectively, between each single year and the year 19971998 (2000-2001). The $\mathrm{CH}_{4}$ growth was taken from the tropospheric growth rate (Simpson et al., 2002). The HF growth rate was deduced from the HALOE $\mathrm{HF} / \mathrm{CH}_{4}$ relationships (Table 1) (Tilmes, 2003). No correction was applied to ozone, as described above. Thus, for winters 19971998 and 2000-2001 in each case two early winter reference relations were derived, one using $\mathrm{HF}$ as the long-lived tracer and one using $\mathrm{CH}_{4}$ (Tables 2 and 3).
3.2 The evolution of tracer-tracer relations during twelve Arctic winters

Active chlorine inside the polar vortex causes chemical ozone loss in the presence of sunlight. Chlorine activation in the Arctic lower stratosphere may be identified as a strong reduction of $\mathrm{HCl}$ compared to normal values. Therefore, using measurements made by HALOE, the evolution of the chlorine chemistry can be inferred from the development of the $\mathrm{HCl}$-tracer relation during each year. The evolution of $\mathrm{HCl}-$ tracer relation and $\mathrm{O}_{3}$-tracer relation is analysed for each of the twelve observed winter periods (Figs. 6 and 7). Low temperatures in the polar vortex cause the formation of PSC and thus control the activation of chlorine and consequently the chemical destruction of ozone. If temperatures are sufficiently low PSCs occur in the polar stratosphere. Therefore, $\mathrm{V}_{\text {PSC }}$ is used here to analyse the interaction between meteorological conditions and development of tracer-tracer relationships for each winter (Fig. 8). Further, a division into cold, moderately cold and warm winters is carried out at the end of this section. Additionally, a measure of the strength of the vortex is determined.

- 1991-1992:

The cold vortex in winter 1991-1992 was disturbed by several warming pulses between November and February (Naujokat et al., 1992). The threshold temperature for PSCs was only reached during January. Therefore, significant ozone depletion can be expected starting in January 1992. At the end of January, a major warming resulted in transport of air into the vortex (e.g. Grooß et al., 2003). However, the vortex in the lower stratosphere was not much affected. The zonal winds at $60^{\circ} \mathrm{N}$ considerably weakened, but remained westerly (Naujokat et al., 1992). In the second part of March and April 1992, ozone loss was found to be homogeneous in the Arctic vortex. This is an indication that the air from outside that entered the vortex at the end of January was well mixed within the vortex during March and April. During March, the temperatures at the North Pole steadily increased and the vortex finally broke down at the end of April (Naujokat et al., 1992). In January, February and at the beginning of March, very low $\mathrm{HCl}$ mixing ratios are clearly noticeable and strong chlorine activation (Fig. 6) occurred in the lower stratosphere. $\mathrm{HCl}$ mixing ratios are nearly zero in January and less than 0.3 ppbv in February below the 0.6 ppbv HF level, which is below the $420 \mathrm{~K}$ potential temperature level.

By April, the $\mathrm{HCl}$ levels increased towards unperturbed values, especially at altitudes below $\approx 420 \mathrm{~K}$. The vortex became steadily weaker during April. From February up to the beginning of April a moderate homogeneous deviation from $\mathrm{O}_{3} / \mathrm{HF}$ reference functions occurred. 

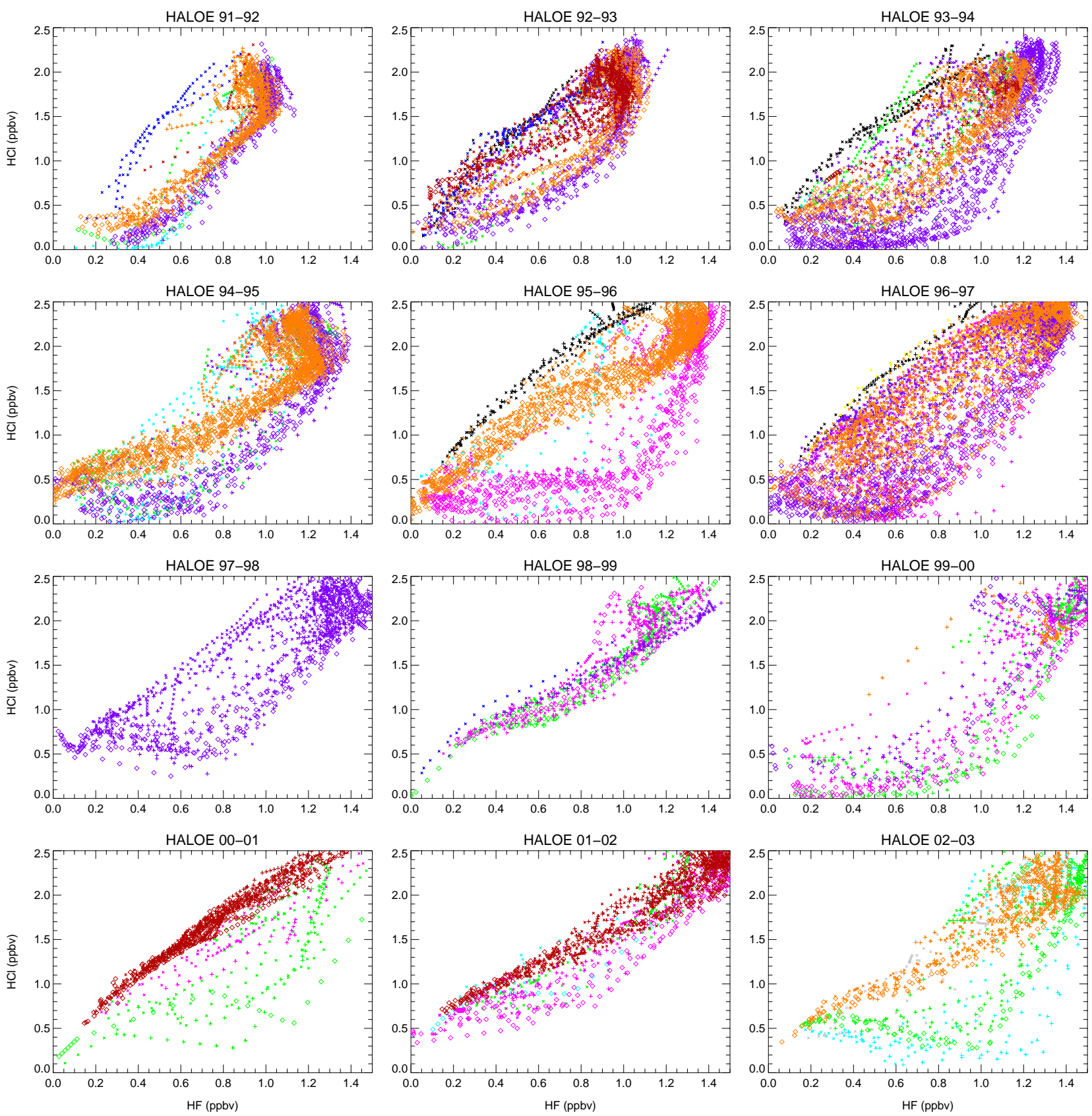

Fig. 6. $\mathrm{HCl} / \mathrm{HF}$ relations are shown for the twelve winters between 1991-1992 and 2002-2003 as measured from profiles inside the vortex core (diamonds), inside the outer vortex (large plus signs), and inside an outer part of the outer vortex (small crosses) by HALOE. Different colours of profiles indicate the different time intervals when profiles were observed: November (black), December (blue), January (cyan), February (green), first part of March (magenta), second part of March (purple), first part of April (orange), second part of April (dark red).

- 1992-1993:

The vortex in winter 1992-1993 was cold and nearly undisturbed until the end of January. A strong minor warming in February shifted the cold air (with low ozone values) towards Europe. This, together with a blocking anticyclone in the troposphere, led to low total ozone values over Europe in February (Nau- jokat and Labitzke, 1993). Conditions for chemical ozone loss were reached because of the low stratospheric temperatures (Fig. 8). Unfortunately, no measurements were taken inside the vortex in February, but $\mathrm{HCl}$ measurements inside the outer part of the vortex boundary region indicate a strong chlorine activation in February at lower altitudes (Fig. 6, small green 

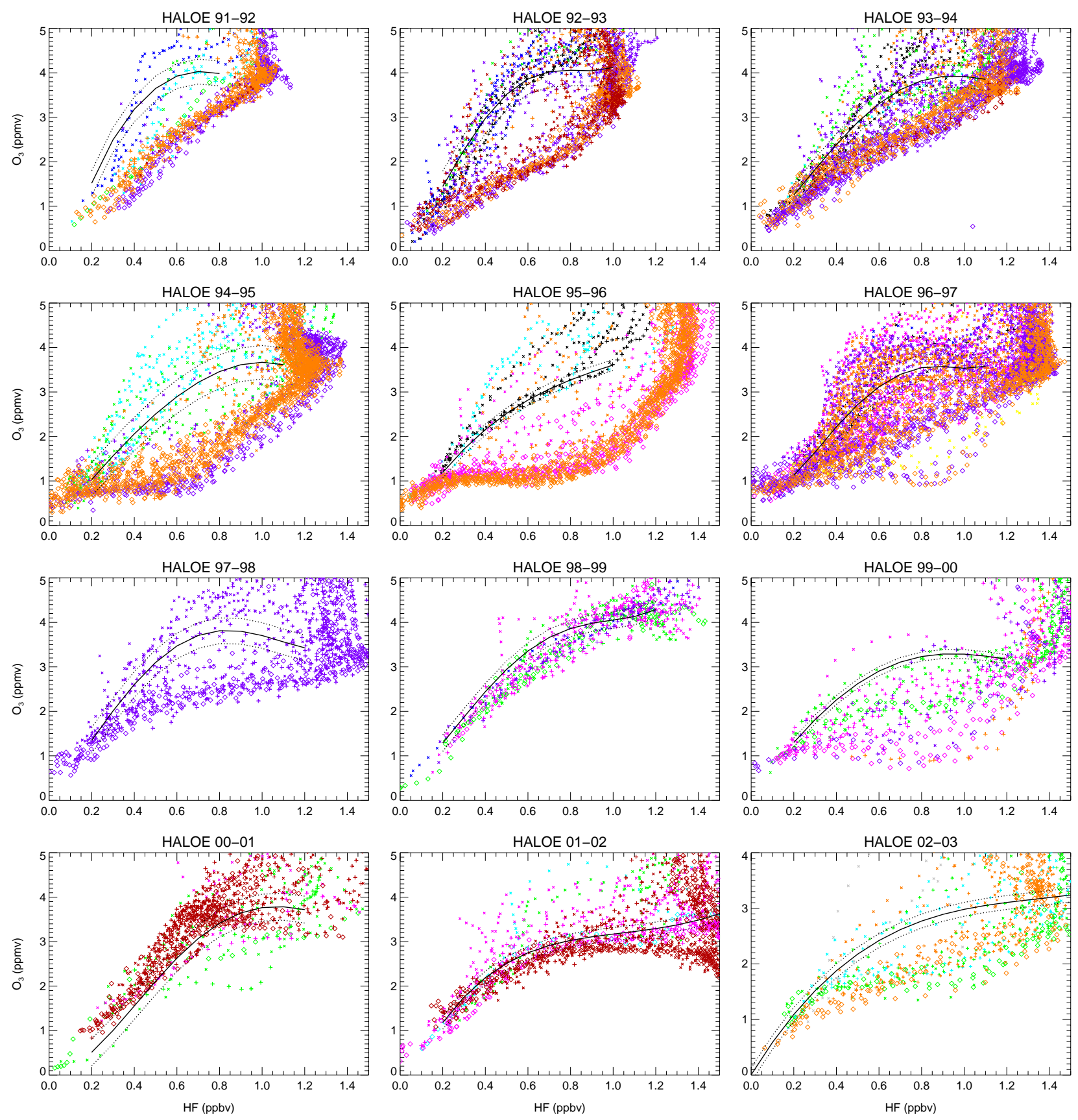

Fig. 7. As Fig. 6 but $\mathrm{O}_{3} / \mathrm{HF}$ relations.

crosses). Temperatures started rising in March and the final break-up of the vortex occurred around 10 April. At that time $\mathrm{HCl}$ levels recovered to unperturbed values. Strong (homogeneous) deviation from the $\mathrm{O}_{3}$-tracer reference function is obvious in March and April (Fig. 7). Until the end of April, the deviation from the $\mathrm{O}_{3} / \mathrm{HF}$ reference function did not further change inside the remaining parts of the vortex.
- 1993-1994:

The early vortex in winter 1993-1994 was slightly disturbed in November, December and January (Naujokat et al., 1995a). Owing to the warming over Europe in February, the vortex was split most of the time. At the end of February and the beginning of March, the vortex air masses cooled down again and temperatures were below the threshold for the existence of PSCs for a few days (Fig. 8). A small decrease of $\mathrm{HCl}$ in February is 

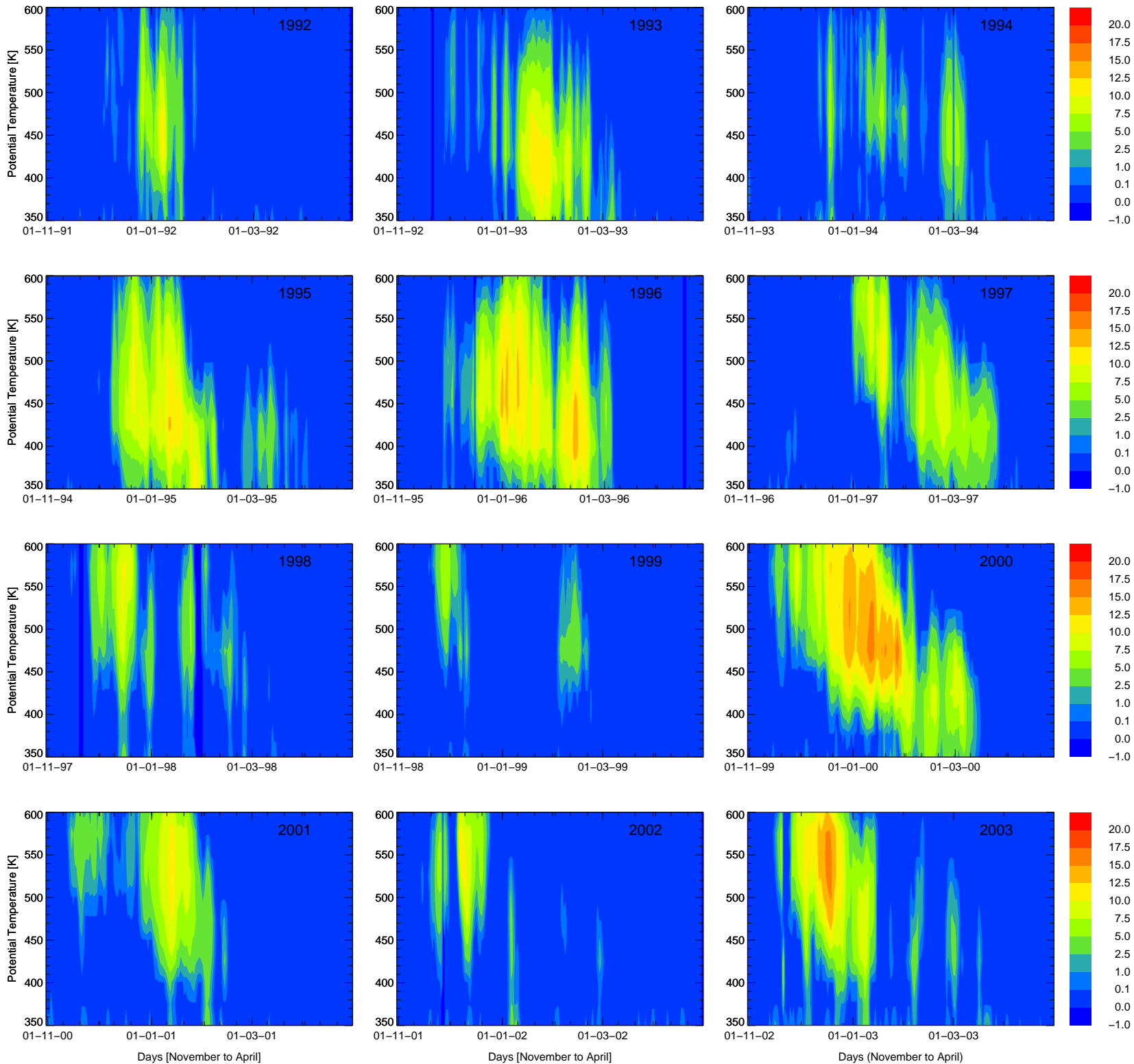

Fig. 8. The volume of possible PSC existence in $10^{6} \mathrm{~km}^{2}$ over the entire polar vortex, as a function of altitude, is shown for the period from November to April for the twelve winters between 1991-1992 and 2002-2003. The PSC threshold temperature was calculated with the analysed UKMO temperatures and pressures assuming typical stratospheric mixing ratios of $\mathrm{HNO}_{3}(10 \mathrm{ppbv})$ and $\mathrm{H}_{2} \mathrm{O}(5 \mathrm{ppmv})(\mathrm{Hanson}$ and Mauersberger, 1988).

noticeable from the $\mathrm{HCl} / \mathrm{HF}$ relation (Fig. 6). Afterwards $\mathrm{HCl}$ strongly decreased during March ( $\mathrm{HCl}$ mixing ratios were below $0.1 \mathrm{ppbv}$ for $\mathrm{HF}$ mixing ratios below $0.7 \mathrm{ppbv}$ ). During April the $\mathrm{HCl}$ levels quickly increased while the vortex became weaker. In March and April moderate deviations from the $\mathrm{O}_{3} / \mathrm{HF}$ reference function became noticeable (Fig. 6), although the chlorine activation in March seemed to be rather pronounced.
- 1994-1995:

The vortex in 1994-1995 formed early and was very cold and strong especially between mid-December and mid-January. A large $\mathrm{V}_{\mathrm{PSC}}$ was deduced for the whole of January 1995. Owing to a warming event in February the vortex was displaced towards Siberia but did not break. The temperatures of the cold centre of the vortex towards Siberia were low enough for PSC formation until 10 February (Naujokat et al., 1995b). Record low temperatures were reached again in the lower stratosphere in March (Naujokat et al., 1995b). In April the 
Table 4. Maximum of the local accumulated ozone loss in ppmv in March (February in 2001, 2003) for the winters between 1991-1992 and 2002-2003 in the altitude range (in $\mathrm{K}$ ), where the loss profile reaches a maximum $\pm 0.1 \mathrm{ppmv}$, is determined employing both the reference relation using $\mathrm{HF}$ and $\mathrm{CH}_{4}$, respectively, as the long-lived tracer for the HALOE measurements inside the entire vortex, with an uncertainty derived from the uncertainty of the early winter reference function. Additionally, the averages between the maximum derived using HF and $\mathrm{CH}_{4}$ as the long-lived tracer are shown.

\begin{tabular}{llllll}
\hline date & tracer & $\begin{array}{l}\text { altitude } \\
\text { range (K) }\end{array}$ & $\begin{array}{l}\text { tracer } \\
\mathrm{CH}_{4}\end{array}$ & $\begin{array}{l}\text { altitude } \\
\text { range }(\mathrm{K})\end{array}$ & $\begin{array}{l}\text { tracer } \\
\text { HF and } \mathrm{CH}_{4}\end{array}$ \\
\hline MF & $2.0 \pm 0.3$ & $390-445$ & $1.9 \pm 0.3$ & $410-450$ & $2.0 \pm 0.4$ \\
March 1993 & $2.2 \pm 0.3$ & $405-460$ & $2.2 \pm 0.2$ & $390-460$ & $2.2 \pm 0.2$ \\
March 1994 & $1.4 \pm 0.2$ & $420-460$ & $1.4 \pm 0.3$ & $400-475$ & $1.4 \pm 0.3$ \\
March 1995 & $2.3 \pm 0.4$ & $420-470$ & $2.5 \pm 0.4$ & $410-460$ & $2.4 \pm 0.5$ \\
March 1996 & $2.2 \pm 0.1$ & $455-515$ & $2.6 \pm 0.3$ & $450-500$ & $2.4 \pm 0.5$ \\
March 1997 & $2.5 \pm 0.2$ & $460-485$ & $2.5 \pm 0.2$ & $460-485$ & $2.5 \pm 0.2$ \\
March 1998 & $1.5 \pm 0.3$ & $410-455$ & $1.4 \pm 0.4$ & $430-510$ & $1.5 \pm 0.5$ \\
March 1999 & $0.8 \pm 0.2$ & $400-480$ & $1.2 \pm 0.2$ & $395-415$ & $1.0 \pm 0.2$ \\
March 2000 & $2.4 \pm 0.1$ & $430-455$ & $2.5 \pm 0.1$ & $410-455$ & $2.5 \pm 0.2$ \\
February 2001 & $1.7 \pm 0.3$ & $475-535$ & $1.7 \pm 0.4$ & $490-515$ & $1.7 \pm 0.4$ \\
March 2002 & $0.5 \pm 0.2$ & $380-540$ & $0.3 \pm 0.2$ & $380-540$ & $0.4 \pm 0.3$ \\
February 2003 & $1.3 \pm 0.1$ & $430-465$ & $1.4 \pm 0.2$ & $410-465$ & $1.4 \pm 0.2$ \\
\hline
\end{tabular}

vortex split and one part rapidly weakened and disintegrated over eastern Asia. The main vortex centre vanished more slowly. As in winter 1992-1993, a strong decrease of $\mathrm{HCl}$ mixing ratio in the outer part of the vortex boundary region was observed by HALOE in February. Although the chlorine activation in March was not as strong as in the previous winter 1993-1994, much stronger deviations from the $\mathrm{O}_{3}$-tracer reference relation in March were observed. During April the $\mathrm{HCl} \mathrm{lev-}$ els increased towards unperturbed values.

- 1995-1996:

The winter 1995-1996 was the coldest recorded by the US National Meteorology Center (NMC) in 18 years (Manney et al., 1996). From December 1995 the stratospheric temperatures in the Arctic remained below the PSC threshold until March. The final warming began in early March. Measurements taken by HALOE in the vortex are available for the first part of March and the first part of April. The strongest chlorine activation in March was observed for this twelve-year overview. In April, $\mathrm{HCl}$ levels almost completely recovered to unperturbed values. The deviation from the early winter reference function $\mathrm{O}_{3} / \mathrm{HF}$ is the same for March and April so that no further ozone loss was identified between March and April.

- 1996-1997:

In winter 1996-1997, the polar vortex formed in November. It was strongly disturbed at the end of November and reformed again during December. Before the vortex was fully established at the end of De- cember, horizontal mixing between air from inside and outside the vortex occurred and the minimum temperature remained above the PSC threshold of $\approx 195 \mathrm{~K}$. After the reformation, the vortex was very cold and strong. At the $475 \mathrm{~K}$ potential temperature level, the lowest temperatures in an 18-year data set were reached in this year in March and April (temperatures were below the PSC threshold until the beginning of April) inside the vortex core (Coy et al., 1997). In March, the vortex core was small and strong whereas the boundary region was wide. PSC occurrence was not possible before January therefore no chlorine activation and thus no ozone loss can be expected in November and December 1996. Until the end of March the temperatures in the polar vortex were low enough for PSC existence (Fig. 8). During mid-February, this potential for chemical ozone loss was enhanced by significant denitrification (Rex et al., 1999a; Kondo et al., 2000). Deviations from the $\mathrm{O}_{3}$ tracer early winter reference function are separated into two parts. The chlorine activation is also rather inhomogeneous with the strongest decrease of $\mathrm{HCl}$ inside the vortex core, except for one profile inside the outer vortex measured in the second part of March (Fig. 6, small purple plus sign). The strongest April decrease of $\mathrm{HCl}$ mixing ratio was observed in this year because the vortex remained intact and cold for an extremely long period.

- 1997-1998:

The vortex in 1997-1998 was slightly disturbed throughout the whole winter. The final warming began in the middle of March (Pawson and Naujokat, 
1999). Minimum temperatures were low enough to activate $\mathrm{HCl}$ during December and during January (Fig. 8). Moderate chlorine activation was observed by HALOE in March and only small deviations from the reference function for $\mathrm{O}_{3}$-tracer occurred. In this winter HALOE data are only available for March inside the polar vortex.

\section{- 1998-1999:}

The winter 1998-1998 was unusually warm due to a major stratospheric warming in mid-December (Manney et al., 1999). The vortex in 1998-1999 was very weak and disturbed. Almost no changes in the $\mathrm{HCl} / \mathrm{HF}$ relation occurred, owing to a small $\mathrm{V}_{\text {PSC }}$ and thus very little chlorine activation at the end of February. However, small deviations from the $\mathrm{O}_{3} / \mathrm{HF}$ early winter reference function were found (see discussion below).

- 1999-2000:

In 1999-2000 the Arctic stratosphere was very cold from the middle of November to late March (Manney and Sabutis, 2000). The lowest values of the February $\mathrm{HCl}$ mixing ratios for any of the observed years were reached owing to the largest $\mathrm{V}_{\text {PSC }}$ during January in the observed period. $\mathrm{HCl}$ mixing ratios are comparable to the low mixing ratios in March 1996. In March 2000, a slight recovery of $\mathrm{HCl}$ levels towards unperturbed values became noticeable, with a total recovery at the end of April. The small deviation from the early winter reference function $\mathrm{HF} / \mathrm{O}_{3}$ in February strongly increased in March and continued up to April.

- 2000-2001:

The vortex in 2000-2001 developed during October and November 2000. A strong Canadian warming at the end of November greatly disturbed the vortex. An undisturbed cold period followed from late December until mid-January. Afterwards, a major warming broke down the vortex in mid-February. During this warming, the vortex drifted over central Europe for a few days and PSC conditions were reached due to a short-term cooling of the vortex. The vortex re-established in March and lasted until April. Strong chlorine activation occurred in February 2001 (Fig. 6). From March to April $\mathrm{HCl}$ levels completely recovered to normal values. In the ozone-tracer relation in February 2001 one profile inside the outer vortex indicates a significant deviation from the early winter reference function. In March and April the early winter reference function is certainly no longer valid, owing to the temporary break-up of the vortex in February, and ozone-tracer profiles scatter above the derived function. Therefore, the TRAC technique cannot be applied to ozone-tracer profiles in March and April.
- 2001-2002:

The winter 2001-2002 was a very warm winter. Although the temperatures at the end of November reached a record minimum for the period 1979-2001, a strong warming in the second half of December occurred so that the vortex significantly weakened. After the vortex re-established in January, it was weak and warm until it broke down in May. Very little chlorine activation is noticeable at the end of March 2002 (Fig. 6) and very little deviation from the $\mathrm{O}_{3} / \mathrm{HF}$ early winter reference relation is apparent at the end of April.

\section{- 2002-2003:}

In this winter the polar vortex formed in November 2002. It was characterised by very low temperatures in the early vortex and chlorine activation already in mid-December 2002 (Tilmes et al., 2003a). VPSC was largest in December for the entire lifetime of the vortex. Afterwards, temperatures increased around midJanuary and the vortex split twice, once in January and once in February. Only a small $\mathrm{V}_{\text {PSC }}$ was derived for the following month. Some chlorine deactivation was deduced from the HALOE measurements in the vortex in February. In April, $\mathrm{HCl}$ had recovered, thus chlorine was completely deactivated. The strongest deviation from the ozone-tracer reference appeared for the profiles in February, and for one profile in April. A detailed analysis of this winter using the TRAC method is described in Tilmes et al. (2003a).

To summarise the temperature conditions for winters between 1991-1992 and 2002-2003, five winters are characterised as being cold (1992-1993, 1994-1995, 1995-1996, 1996-1997 and 1999-2000). These winters show a strong decrease of the $\mathrm{HCl}$ mixing ratio in the $\mathrm{HCl} / \mathrm{HF}$ relation in spring and strong deviations of $\mathrm{O}_{3}$-tracer profiles from the early winter reference function. For the cold winters, the daily $\mathrm{V}_{\mathrm{PSC}}$ average in $400-550 \mathrm{~K}$ between mid-December and March is between $20 \times 10^{6} \mathrm{~km}^{3}$ and $40 \times 10^{6} \mathrm{~km}^{3}$ (shown below in Sect. 6). Moderate deviations from the $\mathrm{O}_{3} / \mathrm{HF}$ reference were found in 1991-1992, 1993-1994, 1997-1998, 2000-2001 and 2002-2003. The daily $\mathrm{V}_{\mathrm{PSC}}$ average is between $5 \times 10^{6} \mathrm{~km}^{3}$ and $15 \times 10^{6} \mathrm{~km}^{3}$. In winters $1998-1999$ and 2001-2002 there was little chlorine activation and very little deviation from the early winter ozone-tracer reference function. The value of the daily $V_{\text {PSC }}$ average does not exceed $3 \times 10^{6} \mathrm{~km}^{3}$ for the very warm winters.

The temperature conditions are closely related to the strength of the vortex. A measure of strength of the vortex can be derived by summarising those days of each year over the entire winter when the poleward boundary of the vortex (as defined by the Nash et al. (1996) criterion) exceeds a certain threshold value of PV. Here $40 \mathrm{PV}$ units (PVU $=10^{-6} \mathrm{~K} \mathrm{~m}^{2} /(\mathrm{kg} \mathrm{s})$ ) at $475 \mathrm{~K}$ is used. For four of the cold winters 1992-1993, 1994-1995,1995-1996 and 

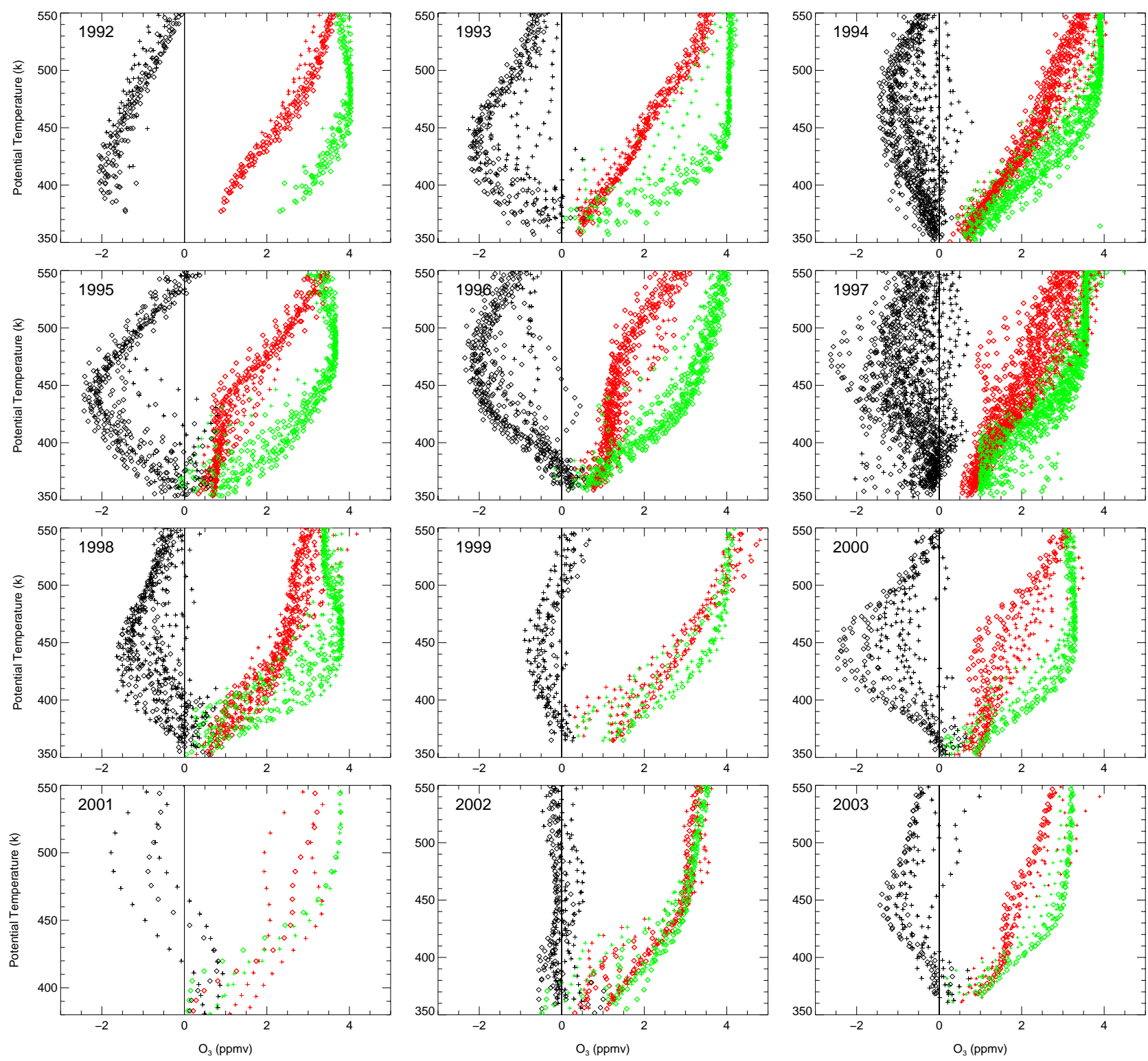

Fig. 9. Vertical profiles (plotted against potential temperature) of $\mathrm{O}_{3}$ mixing ratios (red diamonds) measured by HALOE. The ozone mixing ratios expected in the absence of chemical change $\left(\hat{\mathrm{O}}_{3}\right.$, green diamonds), and the difference between expected and observed $\mathrm{O}_{3}\left(\Delta \mathrm{O}_{3}\right.$, black diamonds) are shown for the winters between 1991-1992 and 2001-2002 in March (2000-2001, 2002-2003 in February). O ${ }_{3}$ was inferred using $\mathrm{HF}$ as the long-lived tracer and the early winter reference functions (Table 2) from profiles inside the vortex core (squares) and inside the outer vortex (plus signs).

1999-2000, this is the case for more than 100 days of the winter; in 1993-1994, 1996-1997 and 2002-2003, it is 8090 days (moderately warm or cold winters), in 1991-1992, 1997-1998, 2000-2001, 2001-2002, 40-63 days (moderately warm or warm winter), and 1998-1999 only 20 days of the year (warm winter).

\section{Ozone loss profiles and column ozone loss}

The chemical ozone loss calculated using the TRAC method should be interpreted as the total amount of ozone destroyed in a period between the time of the early winter reference function and the time of the investigated profile. In this section, calculated local ozone loss profiles in February/March each year are presented, as well as the monthly average column ozone loss over the course of the entire winter for two different altitude ranges. 

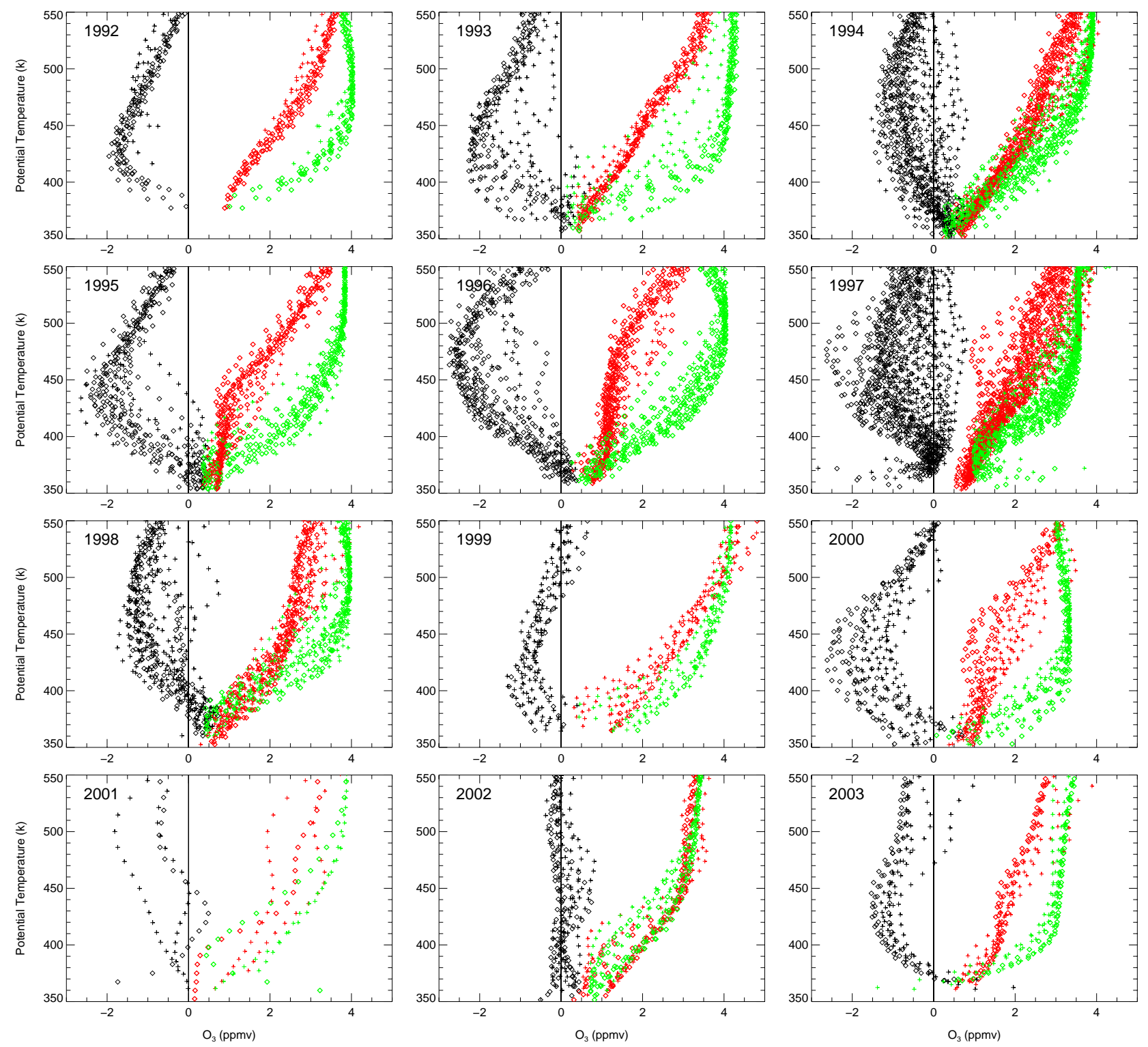

Fig. 10. As in Fig. 9, but with $\mathrm{CH}_{4}$ used as the long-lived tracer and the early winter reference functions (Table 3).

\subsection{Vertical ozone loss profiles}

For each year, the ozone loss profiles differ with respect to the altitude range where ozone loss occurs, the maximum local ozone loss, the altitude where this maximum loss occurs and the extent of homogeneity of the distribution inside the vortex. Vertical ozone loss profiles are calculated using both $\mathrm{HF}$ (Fig. 9) and $\mathrm{CH}_{4}$ (Fig. 10) as the chemically longlived tracer. These ozone loss profiles (black symbols) are calculated as the difference between the actually measured ozone concentration $\mathrm{O}_{3}$ (red symbols) and the corresponding ozone proxy $\hat{O}_{3}$ (green symbols) (e.g. Müller et al., 1996; Tilmes, 2003).
In all winters considered, significant ozone loss mainly arose in the altitude range between 380 and $550 \mathrm{~K}$. At altitudes below $380 \mathrm{~K}$ the uncertainty of calculated ozone loss profiles increased in most winters because of the increasing influence of mixing processes.

The amount of ozone destroyed at different altitudes and, therefore, the shape of the vertical ozone loss profiles depends on the different meteorological conditions inside the polar vortex for each winter. The maximum of the vertical ozone loss profile (in mixing ratio) and the corresponding altitude range (in potential temperature) is shown in Table 4 for March (or February in the years 2001 and 2003) of each year. 
The results derived using two different tracers are within the combined uncertainties for each year. To perform a comparison between the different years, the average of the maximum ozone loss of the two different long-lived tracers is calculated (Table 4, column 6). The strongest local ozone loss of all the years considered, about 2.4 ppmv in 1995-1996 and 2.5 ppmv 1996-1997, was found in the altitude range from about $450-490 \mathrm{~K}$ for both winters. In the cold winters of 1994-1995 and 1999-2000 the maximum of the local ozone loss profiles was similarly strong and it occurred for both of these winters in the altitude range from about $410-460 \mathrm{~K}$. In March 1992 and 1993, local ozone loss is also rather strong, 2.0 ppmv in 1992 and 2.2 ppmv in 1993 at very low altitudes in $390-460 \mathrm{~K}$. Winters termed moderately cold, in the section above, 1991-1992, 1993-1994, 1997-1998 and 20012002, show local ozone loss of about 1.5 ppmv, except for the winter 1991-1992. (The reason for the relatively strong ozone loss in 1991-1992 is discussed below). In 2000-2001 local ozone loss reached $1.7 \mathrm{ppmv}$ from profiles inside the outer vortex in February only, whereas the local ozone loss profiles inside the vortex core did not exceed $1.0 \mathrm{ppmv}$ in February 2000-2001 (Fig. 9). In the warm winters, 19981999 and 2001-2002, the local ozone loss is 1.0 ppmv and 0.4 ppmv, respectively.

As well as the value of the maximum itself, the altitude ranges and the width of the peak of the maximum ozone loss differs from winter to winter corresponding to the location of $\mathrm{V}_{\text {PSC }}$ during the winter. These factors control the amount of column ozone loss calculated by the vertical integration of the ozone loss profile.

In the years 1991-1992, 1992-1993, 1999-2000, 20022003, the ozone loss profiles taken inside the vortex core in March (2002-2003 in February) are very homogeneous (Fig. 10). This is the result of an isolated vortex core with homogeneous ozone loss.

For 1993-1994, 1994-1995, 1995-1996 and 1997-1998, a few profiles of ozone loss indicate a somewhat smaller deviation from the reference function inside the vortex core but the majority of ozone loss profiles inside the vortex core are homogeneously distributed. In 1993-1994 and 1994-1995 a warming in February disturbed the isolated vortex. The vortex shifted off the pole and the cold region was near the edge of the vortex. At this time, rapid ozone destruction occurred at the vortex edge (Manney et al., 2003a). The vortex in 1995-1996 and 1997-1998 was already weakening at the end of February and broke down in March. The ozone loss profiles in 1996-1997 are separated into two distinct parts with moderate loss inside the entire vortex and strong loss in the vortex core (Tilmes et al., 2003b).

The meteorological developments during the winters described above may be responsible for inhomogeneous temperature distributions inside the vortex. They may be responsible for the inhomogeneities in ozone destruction inside the entire vortex, most obvious in winter 1996-1997. In this winter inhomogeneities in temperature resulted in inhomo- geneities in denitrification within the polar vortex (McKenna et al., 2002) that are the likely cause of the inhomogeneities in ozone loss (Schulz et al., 2000; Tilmes et al., 2003b).

For most of the years considered here, the calculated ozone loss profiles for the outer vortex (plus signs in Figs. 9 and 10) show less ozone loss than the profiles in the vortex core. The temperatures inside the outer vortex are generally not as low as inside the vortex core and, therefore, less ozone loss occurred inside the outer vortex than inside the vortex core. In some years (March 1994-1995, 1997-1998, 1998-1999 and February 2000-2001) a very few profiles show slightly stronger deviations from the reference relation and, therefore, stronger ozone loss inside the outer vortex than inside the vortex core. This is possible because exposure to sunlight may be longer inside the outer vortex than inside the vortex core, due to the location of the outer vortex more towards lower latitudes. Further discussion of the differences between ozone loss inside the vortex core and the outer vortex will be given below in Sect. 4.2.

\subsection{Column ozone loss}

Column ozone loss for a twelve-year period was derived by integrating the vertical ozone loss profiles (see Appendix A). This value constitutes a good approximation of the total amount of ozone loss over the entire column of ozone if the vertical integration is extended over a sufficiently large vertical range $(\approx 380-550 \mathrm{~K})$. In this paper, the monthly average column ozone loss is analysed for altitude ranges between 380 and $550 \mathrm{~K}$ and between $400-500 \mathrm{~K}$. Further, a comparison of results of different parts of the polar vortex was performed as well as comparison between the results using different long-lived tracers.

Tables 5 and 6 summarise the column ozone loss in 380 $550 \mathrm{~K}$ and in $400-500 \mathrm{~K}$, respectively, averaged over different months, February, March, April and May (May only in winter 1996-1997), calculated for each year where measurements are available. In February 2000-2001, for two out of three profiles measured inside the entire vortex, ozone loss was found only at altitudes above $\approx 450 \mathrm{~K}$ (Figs. 9 and 10 ). These two profiles scatter above the estimated early winter reference function at altitudes below $450 \mathrm{~K}$ and would wrongly increase the calculated ozone loss. Thus, for this winter the column ozone loss was calculated for the altitude range between 450 and $500 \mathrm{~K}$ only. In Fig. 11 results for the entire vortex are shown, calculated for the altitude range of $380-550 \mathrm{~K}$. The uncertainty of the mean column ozone loss is described by two parameters. The uncertainty which arises solely due to the uncertainty of the early winter reference function is shown as a red error bar in Fig. 11. The standard deviation of the column ozone loss deduced from the individual profiles is shown as a black error bar.

The uncertainty of the early winter reference function is about 15-25 DU in the altitude range of 380-550 K (Table 5) depending on the scatter of profiles inside the early vortex 
Table 5. Column ozone loss (DU) in 380-550 K derived for profiles inside the entire vortex and the vortex core for different months and years (Column 1), using HF (Column 2 and 3) and $\mathrm{CH}_{4}$ as the long-lived tracer (Column 4 and 5). The error was derived from the uncertainty of the early winter reference function and the standard deviation $\sigma$ of the result is shown in brackets. No standard deviation is shown if the column ozone loss had to be calculated from only one profile.

\begin{tabular}{|c|c|c|c|c|}
\hline date & HF: entire $(\sigma)$ & HF: core $(\sigma)$ & $\mathrm{CH}_{4}$ : entire $(\sigma)$ & $\mathrm{CH}_{4}:$ core $(\sigma)$ \\
\hline \multicolumn{5}{|l|}{1992} \\
\hline February & $66 \pm 18$ & $66 \pm 18$ & $68 \pm 17$ & $68 \pm 17$ \\
\hline March & $71 \pm 17(36)$ & $85 \pm 17(30)$ & $58 \pm 16(32)$ & $71 \pm 16(24)$ \\
\hline $\begin{array}{l}\text { April } \\
1993\end{array}$ & $77 \pm 19(11)$ & $73 \pm 19$ (12) & $83 \pm 19(15)$ & $83 \pm 18(15)$ \\
\hline March & $90 \pm 25(25)$ & $104 \pm 24(11)$ & $93 \pm 17(38)$ & $109 \pm 17(27)$ \\
\hline $\begin{array}{l}\text { April } \\
1994\end{array}$ & $89 \pm 26(33)$ & $100 \pm 25(21)$ & $104 \pm 18(30)$ & $117 \pm 17(23)$ \\
\hline February & $16 \pm 19(21)$ & & $4 \pm 23(30)$ & \\
\hline March & $40 \pm 17(17)$ & $48 \pm 16(11)$ & $28 \pm 21(22)$ & $37 \pm 20(16)$ \\
\hline $\begin{array}{l}\text { April } \\
1995\end{array}$ & $44 \pm 19$ (19) & $41 \pm 19(20)$ & $57 \pm 23$ & $56 \pm 23(16)$ \\
\hline March & $79 \pm 24(28)$ & $84 \pm 24(21)$ & $79 \pm 24(27)$ & $83 \pm 23(22)$ \\
\hline $\begin{array}{l}\text { April } \\
1996\end{array}$ & $63 \pm 27(23)$ & $62 \pm 27(23)$ & $76 \pm 26(19)$ & $75 \pm 26(19)$ \\
\hline March & $81 \pm 9(20)$ & $82 \pm 9$ (19) & $102 \pm 22(24)$ & $102 \pm 22(24)$ \\
\hline $\begin{array}{l}\text { April } \\
1997\end{array}$ & $84 \pm 8$ (18) & $87 \pm 8(13)$ & $116 \pm 20(20)$ & $119 \pm 20(14)$ \\
\hline March & $41 \pm 21(25)$ & $52 \pm 20(21)$ & $42 \pm 20(31)$ & $56 \pm 20(26)$ \\
\hline April & $42 \pm 21(29)$ & $61 \pm 20(24)$ & $38 \pm 20(36)$ & $59 \pm 19(28)$ \\
\hline $\begin{array}{l}\text { May } \\
1998\end{array}$ & $69 \pm 19(40)$ & & $74 \pm 18(40)$ & \\
\hline $\begin{array}{l}\text { March } \\
1999\end{array}$ & $48 \pm 21(21)$ & $50 \pm 21(17)$ & $43 \pm 33(21)$ & $47 \pm 32(20)$ \\
\hline February & $28 \pm 13(9)$ & $26 \pm 13(8)$ & $30 \pm 8(20)$ & $28 \pm 8(23)$ \\
\hline $\begin{array}{l}\text { March } \\
2000\end{array}$ & $21 \pm 14(8)$ & $15 \pm 13$ & $40 \pm 8(16)$ & $38 \pm 7(28)$ \\
\hline February & $35 \pm 7$ (19) & $42 \pm 7(7)$ & $41 \pm 16(33)$ & $52 \pm 16(8)$ \\
\hline March & $63 \pm 7(27)$ & $83 \pm 6(13)$ & $73 \pm 15(26)$ & $89 \pm 15$ (17) \\
\hline $\begin{array}{l}\text { April } \\
2002\end{array}$ & $78 \pm 8(7)$ & & $79 \pm 19$ (19) & \\
\hline March & $12 \pm 10(4)$ & $5 \pm 10(9)$ & $-5 \pm 13(13)$ & $0 \pm 13(9)$ \\
\hline $\begin{array}{l}\text { April } \\
2003\end{array}$ & $16 \pm 13(9)$ & $14 \pm 13(13)$ & $3 \pm 16(7)$ & $2 \pm 17(8)$ \\
\hline January & $23 \pm 9(14)$ & & $53 \pm 11(19)$ & \\
\hline February & $37 \pm 9(12)$ & $51 \pm 9(6)$ & $66 \pm 12(13)$ & $81 \pm 12(8)$ \\
\hline April & $44 \pm 10$ & $49 \pm 10(11)$ & $71 \pm 13(6)$ & $74 \pm 13(5)$ \\
\hline
\end{tabular}

from which the reference function was derived. If there is little variability of the mixing ratios of tracers inside the early vortex, the error in the results is smaller than $10 \mathrm{DU}$. This is the case in the year 1995-1996 using HF as the long-lived tracer and in 1998-1999 using $\mathrm{CH}_{4}$ as the long-lived tracer. Differences in the uncertainties of the results derived using two different long-lived tracers in one year are possible, due to the different variability in the two tracers used. If the early winter reference function was derived using only one profile, as is the case in 1999-2000 and 2001-2002, information about the variability of the mixing ratios of tracers inside the early vortex are not included, and the estimated error may be underestimated.

For March 1997 the standard deviation of averaged column ozone loss is larger compared to the other winters and is much larger than the early winter reference error (Fig. 11). At this time, the vortex can be divided into two parts, a part with strong ozone loss and a part with moderate ozone loss (McKenna et al., 2002; Tilmes et al., 2003b). The ozone loss in March 1996-1997 is spatially much more inhomogeneous than the ozone loss observed in all the other winters investigated here (Fig. 9). 
Table 6. Column ozone loss (DU) in the altitude range of 400-500 K (450-500 K in 2000-2001) derived for profiles inside the entire vortex and the vortex core for different months and years (Column 1), using $\mathrm{HF}$ (Column 2 and 3) and $\mathrm{CH}_{4}$ as the long-lived tracer (Column 4 and 5). The error was derived from the uncertainty of the early winter reference function and the standard deviation $\sigma$ of the result is shown in brackets. No standard deviation is shown if the column ozone loss had to be calculated from only one profile.

\begin{tabular}{|c|c|c|c|c|}
\hline date & HF: entire $(\sigma)$ & HF: core $(\sigma)$ & $\mathrm{CH}_{4}$ : entire $(\sigma)$ & $\mathrm{CH}_{4}:$ core $(\sigma)$ \\
\hline \multicolumn{5}{|l|}{1992} \\
\hline February & $50 \pm 11$ & $50 \pm 11$ & $53 \pm 11$ & $53 \pm 11$ \\
\hline March & $54 \pm 11(21)$ & $60 \pm 11(20)$ & $48 \pm 10(21)$ & $55 \pm 10(19)$ \\
\hline April & $53 \pm 12(7)$ & $53 \pm 12(6)$ & $59 \pm 11(6)$ & $60 \pm 11(5)$ \\
\hline \multicolumn{5}{|l|}{1993} \\
\hline March & $68 \pm 15$ (18) & $77 \pm 15(5)$ & $67 \pm 10(21)$ & $78 \pm 10(10)$ \\
\hline $\begin{array}{l}\text { April } \\
1994\end{array}$ & $67 \pm 16(22)$ & $73 \pm 16(13)$ & $74 \pm 11$ (18) & $82 \pm 10(11)$ \\
\hline February & $11 \pm 11(17)$ & & $6 \pm 14(25)$ & \\
\hline March & $27 \pm 10$ & $34 \pm 10(8)$ & $21 \pm 13$ & $27 \pm 13$ (12) \\
\hline $\begin{array}{l}\text { April } \\
1995\end{array}$ & $31 \pm 12(13)$ & $30 \pm 12(12)$ & $42 \pm 14(12)$ & $41 \pm 14(10)$ \\
\hline March & $61 \pm 14(20)$ & $65 \pm 15(14)$ & $61 \pm 14$ (18) & $64 \pm 14(13)$ \\
\hline $\begin{array}{l}\text { April } \\
1996\end{array}$ & \multicolumn{3}{|c|}{1996} & $62 \pm 15$ \\
\hline March & $62 \pm 6(19)$ & $62 \pm 6(19)$ & $78 \pm 14(20)$ & $78 \pm 14$ ( 20$)$ \\
\hline $\begin{array}{l}\text { April } \\
1997\end{array}$ & $64 \pm 5(14)$ & $66 \pm 5(10)$ & $88 \pm 13(16)$ & $91 \pm 12(11)$ \\
\hline March & $31 \pm 13(21)$ & $40 \pm 13(18)$ & $35 \pm 13(26)$ & $46 \pm 12(22)$ \\
\hline April & $30 \pm 13(24)$ & $47 \pm 13(20)$ & $30 \pm 13(29)$ & $47 \pm 12(22)$ \\
\hline $\begin{array}{l}\text { May } \\
1998\end{array}$ & $46 \pm 12(32)$ & & $50 \pm 11$ & \\
\hline $\begin{array}{l}\text { March } \\
1999\end{array}$ & $39 \pm 13(15)$ & $42 \pm 13$ (14) & $36 \pm 20(18)$ & $37 \pm 20(16)$ \\
\hline February & $21 \pm 8(6)$ & $20 \pm 8$ (7) & $24 \pm 5$ (19) & $22 \pm 5(17)$ \\
\hline $\begin{array}{l}\text { March } \\
2000\end{array}$ & $19 \pm 9(8)$ & $13 \pm 8(8)$ & $31 \pm 5(8)$ & $28 \pm 5(14)$ \\
\hline February & $27 \pm 5(18)$ & $42 \pm 7(7)$ & $30 \pm 10(22)$ & $35 \pm 10(3)$ \\
\hline March & $50 \pm 4(22)$ & $67 \pm 4(10)$ & $55 \pm 9(22)$ & $67 \pm 9(12)$ \\
\hline $\begin{array}{l}\text { April } \\
2001\end{array}$ & $77 \pm 5(5)$ & & $80 \pm 11(2)$ & \\
\hline $\begin{array}{l}\text { February } \\
2002\end{array}$ & $10 \pm 5(9)$ & $8 \pm 5$ & $11 \pm 7(8)$ & $6 \pm 6$ \\
\hline March & $1 \pm 7(7)$ & $5 \pm 6(5)$ & $-6 \pm 8(10)$ & $-2 \pm 8(8)$ \\
\hline April & $10 \pm 8(5)$ & $10 \pm 8(4)$ & $4 \pm 10(5)$ & $4 \pm 10$ \\
\hline 2003 & & & & \\
\hline January & $21 \pm 5(13)$ & & $37 \pm 7(13)$ & \\
\hline February & $32 \pm 6(11)$ & $43 \pm 6(5)$ & $47 \pm 7(6)$ & $57 \pm 7(5)$ \\
\hline April & $34 \pm 6(9)$ & $37 \pm 6(5)$ & $52 \pm 7(5)$ & $55 \pm 8(5)$ \\
\hline
\end{tabular}

The error which arises owing to the early winter reference function is significantly smaller in the altitude range of 400$500 \mathrm{~K}$ than in $380-550 \mathrm{~K}$ (Tables 5 and 6). Here, calculated ozone loss for the cold, moderately cold and warm winters between the $400-500 \mathrm{~K}$ level is summarised. In the following, the averages of the results using $\mathrm{CH}_{4}$ and $\mathrm{HF}$ as the long-lived tracers are considered. In 1992-1993, 1994-1995, 1995-1996 and 1999-2000, column ozone loss is 60-80 DU between the 400-500 K level. The maximum of the column ozone loss in this twelve-year study was obtained for the winters 1992-1993 and 1995-1996. In 1996-1997 the strongest mean ozone loss was reached in May (48 DU in the 400$500 \mathrm{~K}$ level). Although the winter 1996-1997 was cold, the mean column ozone loss for this winter $(47 \pm 17 \mathrm{DU}$ inside the vortex core in the $400-500 \mathrm{~K}$ level in April) is comparable with the results of the moderate winters because of the 

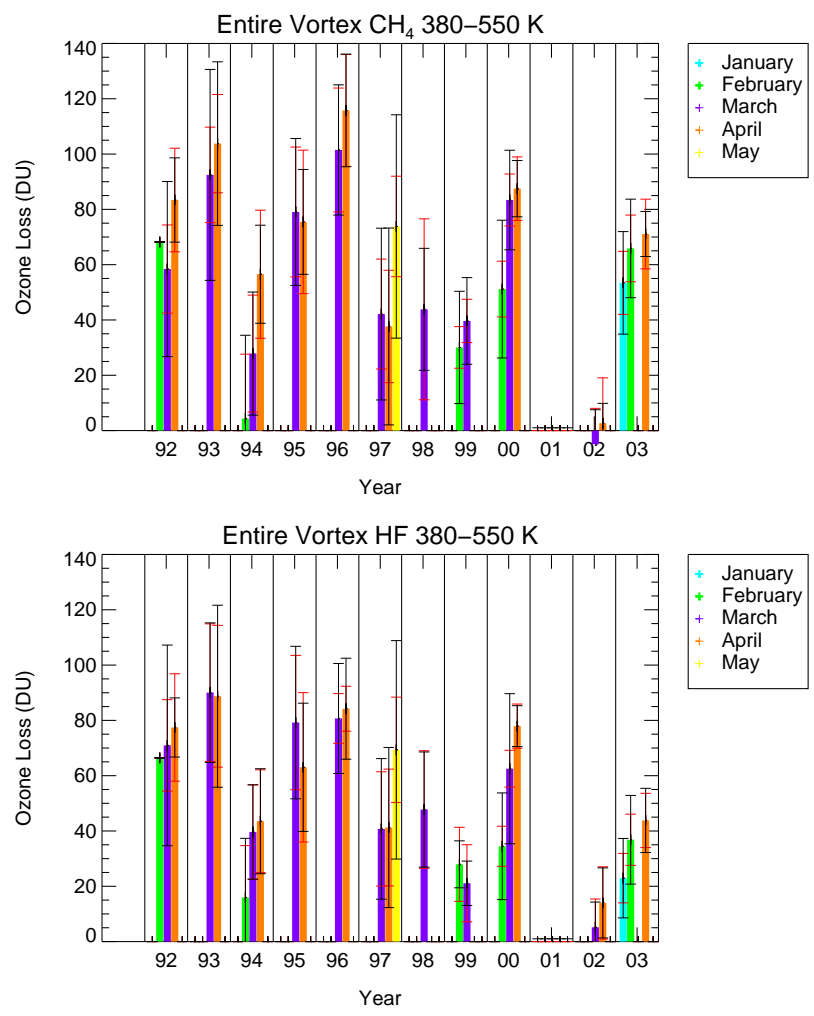

Fig. 11. Monthly averaged column ozone loss derived for profiles inside the entire vortex in 380-550 K, February (green), March (purple), April (orange) and May (yellow) in winters between 1991-1992 and 2002-2003. The red error bar indicates the uncertainty of the early winter reference function, the black error bar the standard deviation. Top panel: $\mathrm{CH}_{4}$ was used as the long-lived tracer, bottom panel: HF was used as the long-lived tracer. Ozone loss was derived from profiles inside the entire vortex.

inhomogeneity of the ozone loss in the vortex. Nonetheless, the maximum local ozone loss of this winter is comparable with results of the cold winters (Fig. 9).

The moderately cold winters 1991-1992, 1993-1994, 1997-1998 and 2002-2003 reach a mean column ozone loss between 31 DU (in winter 1994-1995) and 57 DU (in winter 1991-1992) inside the vortex core in March. (Results of winter 2002-2003 using $\mathrm{CH}_{4}$ as the long-lived tracer are excluded due to uncertain data, as discussed below). In 20002001, the mean column ozone loss was deduced for February in $450-500 \mathrm{~K}$, as described above. Only $10 \mathrm{DU}$ were calculated for the entire vortex. Nevertheless, the maximum column ozone loss reached $20 \pm 4 \mathrm{DU}$ and $21 \pm 6 \mathrm{DU}$ using $\mathrm{HF}$ and $\mathrm{CH}_{4}$ as the long-lived tracers for one profile inside the outer vortex in 450-500 K. In the warm winter 1998-1999 ozone loss still reaches $25 \pm 10 \mathrm{DU}$ derived for an altitude range of 400-500 $\mathrm{K}$ from profiles inside the entire vortex and $21 \pm 10 \mathrm{DU}$ for profiles inside the vortex core. Inside the entire vortex in March 2002 no ozone loss is diagnosed with the TRAC technique within the uncertainty of the early winter reference function.

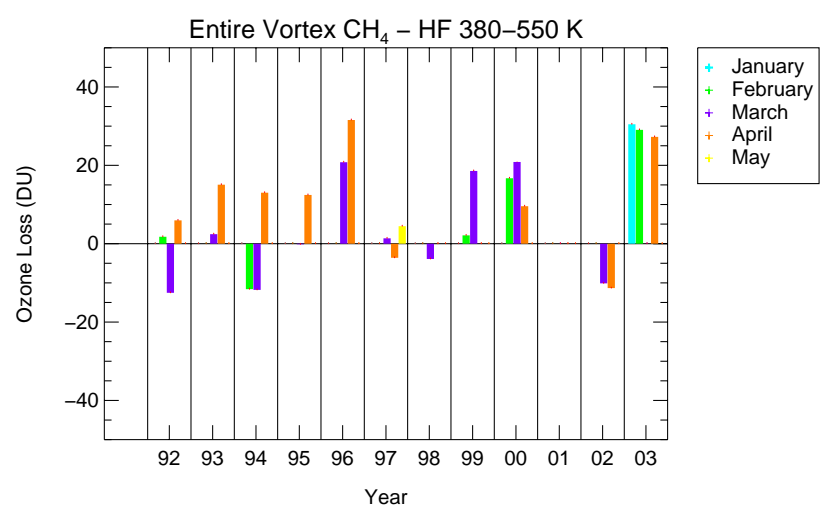

Fig. 12. Difference between monthly averaged column ozone loss derived for profiles inside the entire vortex in 380-500 K using HF and $\mathrm{CH}_{4}$ as the long-lived tracer (see Fig. 11 top and bottom panel). Ozone loss was derived from profiles inside the entire vortex.

The exact mean calculated column ozone loss differs depending on whether $\mathrm{HF}$ or $\mathrm{CH}_{4}$ is used as the long-lived tracer. Further, ozone loss differs depending whether the vortex core or the entire vortex is considered. In Fig. 12, the difference between the ozone loss derived with the two longlived tracers are shown.

The differences between the results using $\mathrm{HF}$ and $\mathrm{CH}_{4}$ as long-lived tracers are $\approx 10-20 \mathrm{DU}$ for most of the observed years and are similar for the entire vortex and the vortex core (not shown). The smallest differences are calculated for winters 1996-1997 and 1997-1998 (below 5 DU). The difference in the early winter reference functions using the two different long-lived tracers are mostly responsible for the different results. In most years observed the results obtained using $\mathrm{CH}_{4}$ as the long-lived tracer agree with those using HF within the uncertainty introduced by the uncertainty of the reference function.

In some years, ozone loss calculated by employing $\mathrm{CH}_{4}$ as the long-lived tracer has a tendency towards larger ozone loss toward the end of the winter compared to HF (Fig. 11). Especially in March 1996, the results differ by more than $30 \mathrm{DU}$ for the entire vortex. In winter 2002-2003 results derived using $\mathrm{CH}_{4}$ as the long-lived tracer are significantly larger (25$30 \mathrm{DU})$ than using HF during the entire winter period. The $\mathrm{CH}_{4}$ mixing ratios inside the Arctic vortex at altitudes below about $450 \mathrm{~K}$ may be problematic in these years, due to signal saturation problems. Such problems are also discussed for the winter 1999-2000 by Müller et al. (2002) and may be responsible for the differences between the results of the two different long-lived tracers used in 2002-2003 (Tilmes et al., 2003a). Therefore, results derived employing $\mathrm{CH}_{4}$ as the long-lived tracer are not discussed in Tilmes et al. (2003a). Also, the significant discrepancies between the results of the two different long-lived tracers in March 1996 may be explained by this problem. 
Table 7. Calculated chemical loss in column ozone loss in the Arctic in winters 1993-1994 to 2001-2002. Comparison between HALOE results and results from other methods.

\begin{tabular}{lccccc}
\hline date & $\begin{array}{c}\text { SAOZ/ } \\
\text { REPROBUS [\%] } \\
\text { in 380-600 K }\end{array}$ & $\begin{array}{c}\text { SAOZ/ } \\
\text { REPROBUS [DU] } \\
\text { in 370-700 K }\end{array}$ & $\begin{array}{c}\text { Match [DU] } \\
\text { in 380-550 K }\end{array}$ & $\begin{array}{c}\text { HALOE [DU] } \\
\text { entire vortex } \\
\text { in 380-550 K }\end{array}$ & $\begin{array}{c}\text { HALOE [DU] } \\
\text { vortex core }\end{array}$ \\
\hline Jan-Mar 1994 & 7 & 31 & & $34 \pm 23$ & $43 \pm 22$ \\
mid-Jan-Mar 1995 & 21 & 95 & $108 \pm 18$ & $77 \pm 27$ & $82 \pm 27$ \\
mid-Jan-Mar 1996 & 20 & 83 & & $92 \pm 25$ & $93 \pm 25$ \\
Jan-Mar 1997 & 22 & 110 & & $46 \pm 22$ & $61 \pm 22$ \\
Jan-Mar 1998 & 12 & 57 & & $36 \pm 35$ & $49 \pm 33$ \\
Dec-Mar 1999 & 5 & 25 & $68 \pm 12$ & $27 \pm 24$ \\
Dec-Mar 2000 & 23 & 105 & $10 \pm 21$ & $86 \pm 15$ \\
Jan-Apr 2002 & 7 & 32 & & & $8 \pm 20$ \\
\hline
\end{tabular}

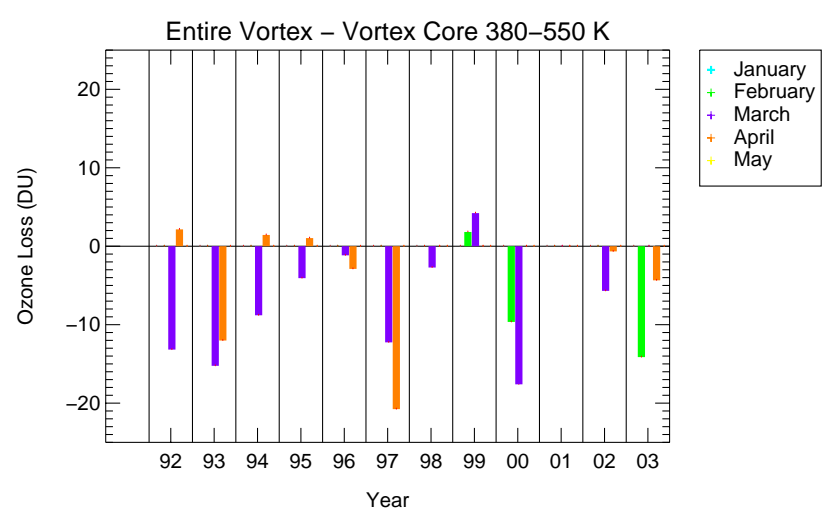

Fig. 13. Difference of monthly averaged column ozone loss between the entire vortex and the vortex core for all winters between 1991-1992 and 2002-2003, using both $\mathrm{CH}_{4}$ and $\mathrm{HF}$ as the longlived tracers. Results were derived in an altitude range of 380$550 \mathrm{~K}$.

Inside the outer vortex, the mean column ozone loss is in most cases less than inside the vortex core (Fig. 13) due to temperature differences, as described above. This effect is very strong for winters 1991-1992, 1992-1993, 1996-1997, 1999-2000 and 2002-2003. As already found considering the vertical ozone loss profiles, in some years the ozone loss is insignificantly greater inside the outer vortex than inside the vortex core (in April 1992, 1994 and 1995, February and March 1999 and February 2001). Further, in some years the standard deviation for profiles in the outer vortex is significantly larger than inside the vortex core (1992-1993, 19941995, 1995-1996 and 1999-2000) (see Tables 5 and 6). That is because the ozone loss inside the outer vortex was much more inhomogeneous than in the vortex core in these winters.

\section{Comparison with ozone loss estimates using different methods}

The results deduced here using the TRAC method are compared with published results obtained by different methods for the determination of chemical ozone loss. Chemical ozone loss in the Arctic vortex in the past decade has been estimated by a variety of methods for different winters (Harris et al., 2002; Newman et al., 2002). However, a comparison between the different ozone loss estimates is only meaningful if the figures compared are determined for exactly the same conditions (Harris et al., 2002).

\subsection{Comparison of column ozone losses}

Column ozone loss from the SAOZ/REPROBUS approach (Goutail et al., 1999; Deniel et al., 1998; Lefèvre et al., 1998) was estimated for a period from December to March/April for winters 1993-1994 to 2002-2003 (Goutail et al., 2000, 2003) at altitudes between 380 and $600 \mathrm{~K}$. The TRAC technique estimates ozone loss between the time when the reference function was derived (see Fig. 1) and the time when HALOE measurements are available in March/April in altitudes between 380 and $550 \mathrm{~K}$. Considering slightly different altitudes for SAOZ and TRAC has little impact on the total column ozone loss. The early winter reference function in winter 1993-1994 was derived from observations at the end of November and at the beginning of January. During these two month no ozone loss was found inside range of uncertainty of the early winter reference function $(\approx 20 \mathrm{DU})$. To compare the results, ozone loss from SAOZ is also considered for the period between January and March 1994. In this winter, SAOZ estimated $\approx 10 \%$ ozone loss in December (Goutail et al., 1999) and $\approx 7 \%$ between January and March. If an average of 441 DU is taken from the inert tracer simulations in March 1994 (pers. comm., F. Goutail, 2004), 31 DU ozone loss is estimated for the period between January and March 1994 from SAOZ (Table 7), which agrees well with 
the accumulated ozone derived from HALOE measurements using the TRAC technique.

In winter 1994-1995, the early winter reference function was derived in mid-January. Therefore, SAOZ ozone loss is estimated for the period between mid-January and March (Goutail et al., 2003) $(\approx 21 \%$ or 95 DU, where 452 DU is the approximated passive ozone). This result is somewhat greater than that derived from TRAC using HALOE observations, although inside the range of uncertainty (Table 7).

The early winter reference function in 1995-1996 was derived from both November and January profiles. As for 1993-1994 no ozone loss was found during these two months within the range of uncertainty. SAOZ accumulated ozone loss in winter 1995-1996 between mid-January and March is $\approx 20 \%$ ( $83 \mathrm{DU}$ ). This value is in good agreement with HALOE results. For 1996-1997 the result from SAOZ agrees with the largest ozone loss calculated by TRAC inside the vortex core (90-110 DU), but the averages do not agree.

In winters 1997-1998 and 1998-1999, the results of SAOZ and TRAC using HALOE data agree within the reported uncertainty. The estimated ozone loss from SAOZ in winters 1999-2000, 2001-2002 is $\approx 20$ DU larger than derived here from TRAC.

The very large ozone loss rates in the early winter 19931994, 1994-1995, 1995-1996 and 1997-1998 derived by SAOZ can neither be confirmed nor falsified using HALOE measurements due to the lack of observations. However, in the TRAC analysis there is no sign of such strong ozone losses as deduced by SAOZ in January 1993-1994 and 19951996, when HALOE measurements are available only within the vortex boundary region.

Chemical ozone loss was derived by the Match technique for the winter 1994-95 (Rex et al., 1998; Schulz et al., 2000) for the period between January 1 and March 1995, in 370$700 \mathrm{~K}$. It is more than $40 \mathrm{DU}$ larger $(127 \pm 14 \mathrm{DU})$ than that with HALOE (in 380-550 K). Like SAOZ, the Match technique estimated strong ozone loss during the first two weeks in January. Because the temporal evolution of ozone destruction estimated by SAOZ and Match coincides quiet well (Rex et al., 1998) in this year, we assume that about one third of the ozone loss derived by Match occurred during the first half of January. This results in accumulated ozone loss of $108 \pm 18 \mathrm{DU}$ estimated from Match results, which agrees with HALOE results within the range of uncertainty (Table 7).

The column ozone loss from UARS microwave limb sounder (MLS) measurements for March (end of February 1997) of the winters 1991-1992 to 1996-1997 was calculated for above $100 \mathrm{hPa}$ (Manney et al., 2003a). These results are compared with HALOE results derived for the altitude range of 40 to $100 \mathrm{hPa}$ (Table 8) to allow a direct comparison with the MLS results. The results of the two methods agree in so far as the strongest ozone loss was found for the winters 1995-1996 and 1992-1993. Nevertheless, significant differences occur because the time intervals considered using the two techniques are not exactly the same (Manney et al., 2003a). The strongest discrepancies arise for the winters 1991-92 and 1994-95 (see Table 8, fifth column).

In 1991-1992 the ozone loss from MLS was derived in a period between 12 January and 22 March 1992 (Manney et al., 2003a). At the beginning of January 1992, a large $\mathrm{V}_{\mathrm{PSC}}$ and significant solar insolation already existed. Therefore ozone loss occurred before the start of the calculation using MLS measurements, which at least partly explains the larger ozone loss deduced from TRAC compared to MLS. Ozone loss in winter 1994-1995 was estimated in the period between 21 December 1994 and 10 March 1995 using MLS observations. The second part of March PSCs are possible at altitudes below $500 \mathrm{~K}$ (see Fig. 1) and the vortex was strongly illuminate in spring. Ozone loss calculated for March 1995 using the TRAC method includes the loss in the second part of March, whereas MLS calculations stopped at 10 March 1995. Therefore, significantly smaller ozone losses were estimated using MLS.

For the winter 1992-1993, MLS calculations were started one month later than here using HALOE measurements. Indeed, results derived using MLS data are slightly lower. In winter 1993-1994 and 1995-1996, the ozone losses determined from MLS data and HALOE measurements are well inside the range of uncertainty. A quite similar period was considered for both methods to derive chemical ozone loss. In 1996-1997, MLS calculations of ozone loss stopped at the end of February 1997. However, in March significant ozone loss can be expected (Tilmes et al., 2003b; Terao et al., 2002). Although, ozone loss deduced with the two approaches fits very well in this winter considering the entire vortex, MLS ozone loss is significantly smaller considering the vortex core.

In summary, all the differences occurring between ozone loss derived using MLS data, on the one hand, and the TRAC method using HALOE data, on the other hand, can be explained by the fact that different time intervals are considered for the derivation of chemical ozone loss.

In winter 1999-2000, the column ozone loss inside the Arctic was derived from various measurements and by different techniques because an extensive measurement campaign was conducted: SOLVE-THESEO 2000 (Newman et al., 2002). The ozone loss calculated between early January and mid-March by the Match technique is $71 \pm 12 \mathrm{DU}$ (Rex et al., 2002). Results from the OMS balloon measurements (Salawitch et al., 2002) were calculated up to 5 March 2000 as $61 \pm 14$ DU. An extrapolation of the result for 5 March to mid-March (based on Match-derived ozone loss rates (Müller et al., 2002) yielded $84 \pm 13$ DU. Ozone loss from POAM/REPROBUS was determined as $80 \mathrm{DU}$ in 380-700 K, as reported by Harris et al. (2002). These results agree well with the column ozone loss found in the present work ( $86 \pm 15 \mathrm{DU}$ in $380-550 \mathrm{~K}$ inside the vortex core). 
Table 8. Calculated chemical loss in column ozone loss (DU) in the Arctic over seven winters, HALOE results and MLS results (Manney et al., 2003a) are compared.

\begin{tabular}{lllll}
\hline date & MLS $^{\mathrm{a}}$ & $\begin{array}{l}\text { HALOE } \\
\text { entire vortex } \\
\text { in 100-40 hPa }\end{array}$ & $\begin{array}{l}\text { HALOE } \\
\text { vortex core } \\
\text { in 100-40 hPa }\end{array}$ & $\begin{array}{l}\text { HALOE - MLS } \\
\text { entire vortex }\end{array}$ \\
\hline March 1992 & 29 & $56 \pm 15$ & $57 \pm 15$ & $27 \pm 15$ \\
March 1993 & 54 & $67 \pm 16$ & $77 \pm 16$ & $13 \pm 16$ \\
March 1994 & 35 & $26 \pm 15$ & $34 \pm 15$ & $-9 \pm 15$ \\
March 1995 & 36 & $68 \pm 17$ & $73 \pm 17$ & $32 \pm 17$ \\
March 1996 & 63 & $74 \pm 20$ & $75 \pm 20$ & $11 \pm 20$ \\
February 1997 & 35 & $35 \pm 14$ & $45 \pm 13$ & $0 \pm 14$ \\
\hline
\end{tabular}

a Taken from Manney et al. (2003a), Table 3

Table 9. Accumulated ozone loss estimated by MLS over the calculation period in $465 \mathrm{~K}$ and $520 \mathrm{~K}$ taken from Manney et al. (2003a), Tables 1 and 2. HALOE results at $465 \mathrm{~K}$ and $520 \mathrm{~K}$ inside the vortex core were estimated from Figs. 9 and 10; in February 1997 no HALOE observations are available and, therefore, no ozone loss could be derived for February.

\begin{tabular}{lcccc}
\hline date & $\begin{array}{c}\text { ozone loss } \\
\text { 465 K (MLS) }\end{array}$ & $\begin{array}{c}\text { ozone loss } \\
\text { 465 (HALOE) }\end{array}$ & $\begin{array}{c}\text { ozone loss } \\
\text { 520 K (MLS) }\end{array}$ & $\begin{array}{c}\text { ozone loss } \\
\text { 520 K (HALOE) }\end{array}$ \\
\hline March 1992 & 0.5 & 1.4 & 0.3 & 0.4 \\
March 1993 & 1.0 & 1.8 & 0.7 & 0.8 \\
March 1994 & 0.5 & 0.9 & 0.7 & 0.7 \\
March 1995 & 0.8 & 1.8 & 0.2 & 0.7 \\
March 1996 & 1.3 & 1.9 & 1.4 & 1.6 \\
\hline
\end{tabular}

\subsection{Comparison of accumulated local ozone losses}

Accumulated local losses in the vortex in mixing ratios were estimated at certain altitudes for various time periods and for given subsiding layers of air from the MLS observations (Manney et al., 2003a), by the Match technique (Rex et al., 1998; Schulz et al., 2000) and by Knudsen et al. (1998) using the vortex average approach. The results should be comparable with the accumulated local ozone loss derived by the TRAC technique if the time interval considered is comparable.

The accumulated chemical ozone loss was calculated from MLS observations for winters 1991-1992 to 1995-1996 from December/January to the end of March at the $465 \mathrm{~K}$ and $520 \mathrm{~K}$ level (Manney et al., 2003a) (Table 9). Local ozone loss at the $465 \mathrm{~K}$ level derived from HALOE data is consistently $\approx 1$ ppmv greater in winter 1991-1992 and 1995-1996 than that derived from MLS observations (see Table 9, column 2 and 3). Differences between the two approaches in the other winters considered are less, but still significant. For the $520 \mathrm{~K}$ level, results do not differ significantly except for the winter 1995-1996. The reason for possible differences between MLS and TRAC results was given in Section 5.1.
Further, it has to be taken into account that an instrument like MLS has a low vertical resolution and the exact altitude is difficult to estimate.

For the years 1992, 1995, 1996 and 2000, largely unexplained stratospheric ozone loss rates during January were found, using a combination of data from Match, POAM II, POAM III and MLS (e.g. Hansen et al., 1997; Becker et al., 1998, 2000; Rex et al., 2003a; Kilbane-Dawe et al., 2001). Here, only a limited assessment of the problem is possible because of the lack of regular sampling of the polar vortex in January by HALOE. Based on HALOE observations, significant ozone loss in January is apparent only in 19911992. In 1995-1996, no significant ozone loss could be found inside the vortex boundary region. However, very small ozone losses occurring, for example, in mid-winter and during warm winters cannot be determined with sufficient accuracy by the TRAC method due to a certain uncertainty range of the reference function. No measurements are available in 1994-1995 and 1999-2000 to calculate chemical ozone loss during early winter. Considering the daily sun hours at $A_{P S C}$ for January of these winters, this APSC was strongly illuminated during the whole of January 1991, and only at the end of January 1995, 1996 and 2000 (see Fig. 1). 
In winter 1996-1997, accumulated ozone loss was estimated in the period between the end of January and the end of March by the Match technique (1.1 ppmv) and by using the vortex average approach $(0.9 \pm 0.2 \mathrm{ppmv})$ at the $455 \mathrm{~K}$ potential temperature level (Harris et al., 2002). Such values are in agreement with the moderate ozone loss within the range of uncertainty deduced from ILAS $0.5-1.0 \mathrm{ppmv}( \pm 0.2 \mathrm{ppmv})$ and HALOE $0.9-1.4 \mathrm{ppmv}( \pm 0.2 \mathrm{ppmv})$ at the $475 \mathrm{~K}$ level (Tilmes et al., 2003b). Further calculations of ozone loss were performed by the Match technique based on ILAS observations for the winter 1996-1997 (Terao et al., 2002). There, the integrated ozone loss during February and March reached $2.0 \pm 0.1 \mathrm{ppmv}$ at $475-529 \mathrm{~K}$ levels. This result is in good agreement with the maximum of the ozone loss profile of $2.0 \pm 0.3$ ppmv derived from ILAS by the TRAC technique in a similar altitude range (Tilmes et al., 2003b).

However, in winter 1996-1997 vortex average losses obtained by different methods are very difficult to compare because ozone loss inside the vortex was spatially very inhomogeneous (McKenna et al., 2002; Schulz et al., 2000; Tilmes et al., 2003b). Thus, the averages derived will greatly depend on what fraction of the data entering the average originates from the vortex region showing the stronger ozone loss.

In 1999-2000 HALOE local ozone loss in 430-450 K $(2.3 \pm 0.2 \mathrm{ppmv})$ is in good agreement with the accumulated ozone loss in the vortex in mid-March derived by the Match technique (2.0 $\pm 0.3 \mathrm{ppmv})$ (Rex et al., 2002). The ozone and the tracer measurements between early January and midMarch 2000 from the ER-2 were used to deduce chemical ozone loss (1.8 \pm 0.3 ppmv) (Richard et al., 2001). Ozone loss deduced from POAM III satellite measurements only reached $1.5 \pm 0.3$ ppmv for mid-March (Hoppel et al., 2002).

The accumulated ozone loss derived using the vortex average approach (Rex et al., 2004) agrees most closely with the results derived using the TRAC technique, as will be described below in detail in Sect. 6 .

\section{Impact of meteorological conditions on ozone loss}

Arctic ozone loss is related to the particular meteorological and dynamic conditions of the polar vortex in each year. The twelve-year time series of ozone loss obtained in a consistent manner in this paper allows this question to be addressed in detail. In this section, the relationship between accumulated ozone loss and the volume of possible PSC existence ( $\mathrm{V}_{\mathrm{PSC}}$ ) - also referred to as potential volume of PSCs (Rex et al., 2004) - will be derived and compared with the results of the first study (Rex et al., 2004) of this relationship. Further, the impact of different factors - such as the amount of solar illumination on PSC area - on ozone loss are discussed in detail.
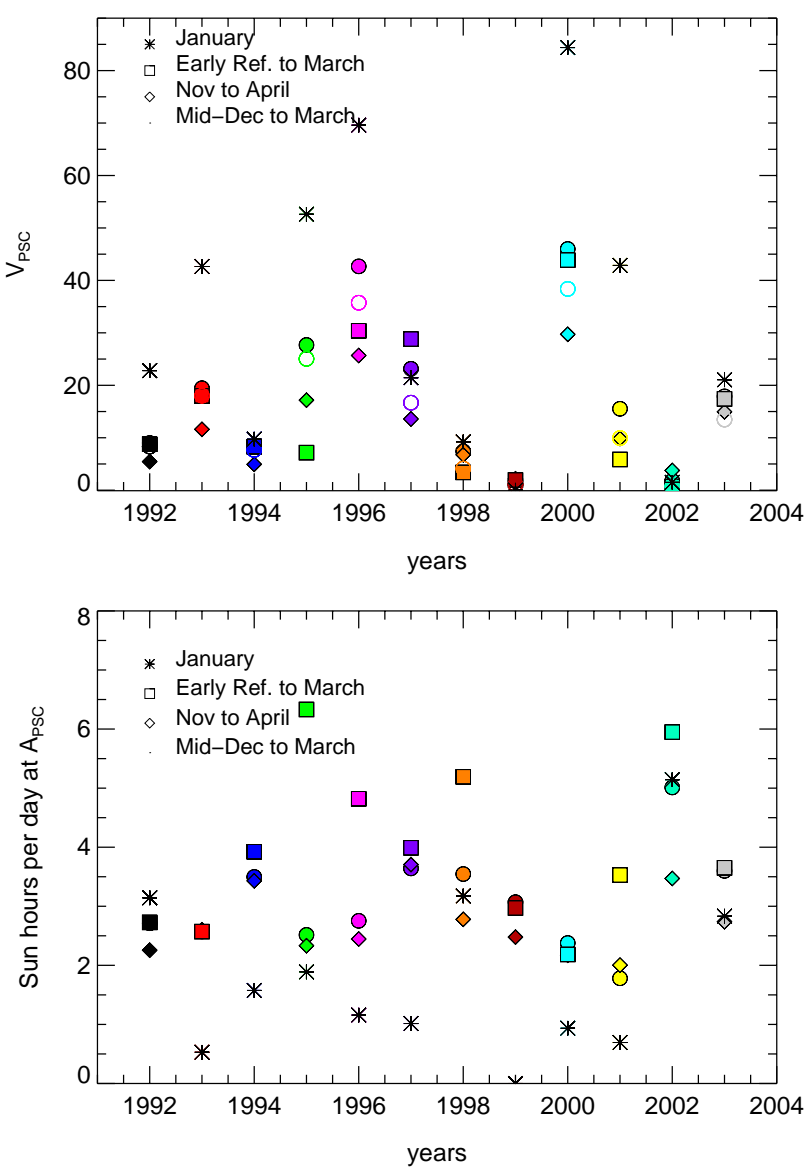

Fig. 14. Daily mean $V_{P S C}$ (top panel) and sun hours at possible area of PSC existence, VPSC (bottom panel) averaged between 400$550 \mathrm{~K}$ in the Arctic polar vortex using UKMO data for the years 1991-1992 to 2002-2003 in different colours. Different symbols indicate different time intervals for calculating the averaged daily mean: stars: entire January; filled squares: from early winter reference function to end of March; filled diamonds: entire winter period; filled circles: mid-December to end of March; open circles: mid-December to end of March (Rex et al., 2004).

Before referring to the relationship between accumulated ozone loss and $\mathrm{V}_{\mathrm{PSC}}$, each of these values will be discussed separately. Accumulated ozone loss in DU and in mixing ratios was estimated in the pervious sections for different time intervals depending on available measurements inside the polar vortex core. In detail, the results were derived for the period between the date of the early winter reference function - varying each year (see Fig. 1) - and February, March and April. In the following, accumulated ozone loss calculated for March (in 2000-2001 and 2002-2003 for February) is considered in altitude ranges between 380 and $550 \mathrm{~K}$ and between 400 and $500 \mathrm{~K}$. Ozone loss of the winter 2000-2001 was derived for an altitude range of $450-500 \mathrm{~K}$ only (as described in Sect. 4.2). Further, the results of the very warm winter 2001-2002 have a large uncertainty that can only be 


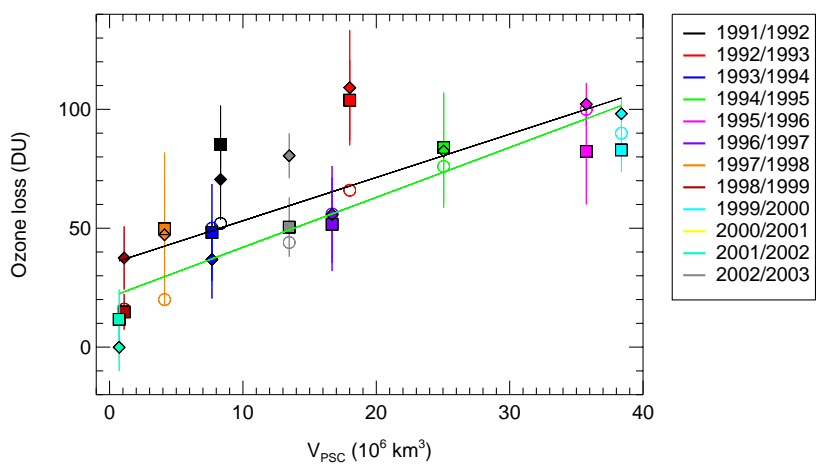

Fig. 15. Relation between the accumulated ozone loss in DU and $V_{\text {PSC }}$ in the Arctic polar vortex for the years 1991-1992 to 2002-2003 in different colours. Monthly averaged ozone loss inside the vortex core in March (February 2002-2003) between 380 $550 \mathrm{~K}$ (winter 2000-2001 is not included) using the TRAC method; coloured solid squares (HF is used as the long-lived tracer) and solid diamonds $\left(\mathrm{CH}_{4}\right.$ is used as the long-lived tracer). Ozone loss derived by the vortex average approach (Rex et al., 2004) is shown in coloured open circles for the same altitude range. $\mathrm{V}_{\mathrm{PSC}}$, taken from Rex et al. (2004), was averaged between mid-December to March of each year and between 400-550 K derived from ECMWF data. Black line indicates a linear relation between $\mathrm{V}_{\text {PSC }}$ and ozone loss from the TRAC method. Green line indicates the linear relation between $\mathrm{V}_{\mathrm{PSC}}$ and ozone loss from the vortex average approach reported by Rex et al. (2004).

poorly quantified because the vortex was not isolated and these results are not considered. Additionally, the results of winters 1997-1998 and 2000-2001 have to be regarded with caution because the early winter reference functions had to be derived from the climatology values.

The PSC occurrence varies for different winters depending on the evolution of temperature and dynamics of the polar vortex (Fig. 8). To compare PSC occurrences, an average value over a certain time interval and a certain altitude range has to be calculated. These averaged $\mathrm{V}_{\text {PSC }}$ values strongly depend on the time interval considered (see Fig. 14).

In Fig. 14, top panel, the daily average $V_{\text {PSC }}$ are shown for different time intervals. The calculation of $\mathrm{V}_{\mathrm{PSC}}$ over the entire winter period from November to the end of April indicates the temperature conditions for the entire winter. Based on $V_{P S C}$, a classification of the Arctic winters into cold, moderately cold, and warm winters is possible (see end of Sect. 3).

Each winter differs decisively in the temperature evolution. Some winters are very cold in January (1999-2000), (Fig. 14, top panel, filled squares), whereas others are much colder in December (2002-2003) or in February and March (1996-1997). This information cannot be captured in an average of the entire winter, nor is it covered in an average between mid-December and the end of March, as used by Rex et al. (2004). Further, the difference between $V_{P S C}$ averaged for different time intervals in any given year strongly depends on the year considered.
As the daily average $\mathrm{V}_{\text {PSC }}$ is derived for different time intervals, sun hours per day are averaged on a possible area of PSC (APSC) based on UKMO meteorological analysis (Fig. 14, bottom panel). The amount of solar insolation at only the cold parts of the polar vortex depends on the time interval considered as well. During January, sun hours per day vary between 0.5 sun hours per day (1992-1993) up to 5 sun hours per day in winter 2001-2002. Sun hours per day averaged for the time interval between the time of the early winter reference function and the end of March vary between 2 sun hours per day in winter 1999-2000 up to above 6 sun hours per day in winter 1994-1995. The influence of the variations of solar insolation between different years will be discussed further below.

The relationship between accumulated ozone loss and the daily average $\mathrm{V}_{\text {PSC }}$ has been reported by Rex et al. (2004). They averaged $V_{\text {PSC }}$ in the time interval between mid-December and the end of March based on meteorological analysis from ECMWF (Fig. 14, top panel, coloured open circles). In the present study, $\mathrm{V}_{\mathrm{PSC}}$ was determined from the UKMO analysis in the same altitude range (400-550 K) and in the same time interval as by Rex et al. (2004) (Fig. 14, top panel, filled circles). Some differences arise between $V_{\text {PSC }}$ derived from Rex et al. (2004) and this study. This is possibly owing to the different meteorological analysis used (Manney et al., 2003a).

Accumulated ozone loss in mixing ratios calculated using the vortex average approach is averaged between day 15 and day 85 of a particular year in a vertical region between 14 and $24 \mathrm{~km}$ (Rex et al., 2004). In winter 1994 and 1999 the time interval of days 25 to 85 was chosen (late establishment of the vortex). In winter 1992, 1998 and 2003 the time interval of days 15 to 75 was chosen (early break up). The lower limit of the range is $380 \mathrm{~K}$ and the upper limit is $\approx 550 \mathrm{~K}$.

The accumulated ozone loss derived using the vortex average approach (Rex et al., 2004) and the results derived in this study are comparable using ozone loss derived in $380-550 \mathrm{~K}$. The relationship between these results and the daily average $\mathrm{V}_{\text {PSC }}$ derived by Rex et al. (2004) is shown in Fig. 15.

The green line indicates the linear relationship reported by Rex et al. (2004). HALOE ozone loss values show a quite similar relationship. The slope (black line) is somewhat less (1.8 DU per $10^{6} \mathrm{~km}^{3}$ ) compared to the green line (2.1 DU per $10^{6} \mathrm{~km}^{3}$ ) owing to the much larger ozone loss values of the winters 1991-1992 and 1992-1993 derived using the TRAC method. Accumulated ozone loss of the two approaches is well inside their range of uncertainty (reported uncertainty of the vortex average approach is 10-15 DU), except for the winters 1991-1992 and 1992-1993. These two winters show significant deviations from the linear relations that are possibly due to the impact of an enhanced stratospheric aerosol content in these years, as will be discussed below. This influence was also found by Rex et al. (2004), although it is much smaller (with a maximum of $\approx 10 \mathrm{DU}$ for total ozone loss calculated between 14 and $24 \mathrm{~km}$ ) than that derived here. 
One reason for the discrepancy between the two approaches may be that Rex et al. (2004) started their ozone loss calculation at day 15 (25) of the year in question. This is about one month later than the start of ozone loss calculation using the TRAC method (Fig. 1). Especially in 1991-1992, a large PSC volume and significant solar insolation already existed before day 15 of the year 1992 (as already discussed comparing HALOE and MLS results). For the same reason, the average approach may calculate smaller values of ozone loss in winters 1992-1993, 1993-1994, 1997-1998, and 20022003 (winter 2000-2001 and 2001-2002 were not considered) (see Fig. 15). On the other hand, in winters 1994-1995 and 1995-1996 the start of ozone loss calculation was later using the TRAC technique compared to the vortex average approach, and PSCs and significant daily solar radiation were present before this time. Therefore, ozone loss derived using TRAC should be smaller compared to the result of the vortex average approach. The described discrepancies (except for the winter 1994-1995) are obvious in Fig. 15, although in most of the years considered the error bar is much larger than the discrepancies.

Considering a time interval for estimating $\mathrm{V}_{\mathrm{PSC}}$ from midDecember to the end of March, further important factors controlling ozone loss are masked by averaging $\mathrm{V}_{\mathrm{PSC}}$ over nearly the entire winter. In the next part of this section, different time intervals to average $\mathrm{V}_{\text {PSC }}$ will be used to perform a comparison between chemical ozone loss calculated using the TRAC method and $\mathrm{V}_{\text {PSC }}$. For this purpose, both parameters (ozone loss and $\mathrm{V}_{\mathrm{PSC}}$ ) are estimated in the same time interval between the time of the early winter reference function and the end of March (February in 2000-2001 and 2002-2003) using the TRAC technique. Further, accumulated ozone loss was derived for an altitude range of $400-500 \mathrm{~K}$, because here the error is less compared to larger altitude ranges using the TRAC method (see Sect. 2.2). As described above, results of the winters 1997-1998 and 2000-2001, and especially of the very warm winter 2001-2002, have to be regarded with caution.

Under these conditions, ozone loss and $\mathrm{V}_{\mathrm{PSC}}$ show a linear relationship as well. This relationship is derived from all the values shown in Fig. 16. The slope is 1.1 DU per $10^{6} \mathrm{~km}^{3}$ using accumulated column ozone loss and $0.7 \mathrm{ppmv}$ using ozone loss in mixing ratios averaged between 400 and $500 \mathrm{~K}$ (Fig. 16, black lines). The slope is less than in Fig. 15, because ozone loss was derived in a smaller altitude range. Further, a stronger deviation from a linear relationship occurs. Especially the winter 1994-1995 deviates significantly from the derived linear relationship.

Besides $\mathrm{V}_{\mathrm{PSC}}$, chemical ozone destruction is expected to be influenced by the duration of the exposure to sunlight of the cold vortex regions, because solar radiation is involved in ozone-destroying cycles. Additionally, this effect was already found for the January ozone loss in Sect. 3.1

To separate different factors controlling ozone loss, and thus to eliminate the effect of $\mathrm{V}_{\mathrm{PSC}}$ on ozone depletion, we
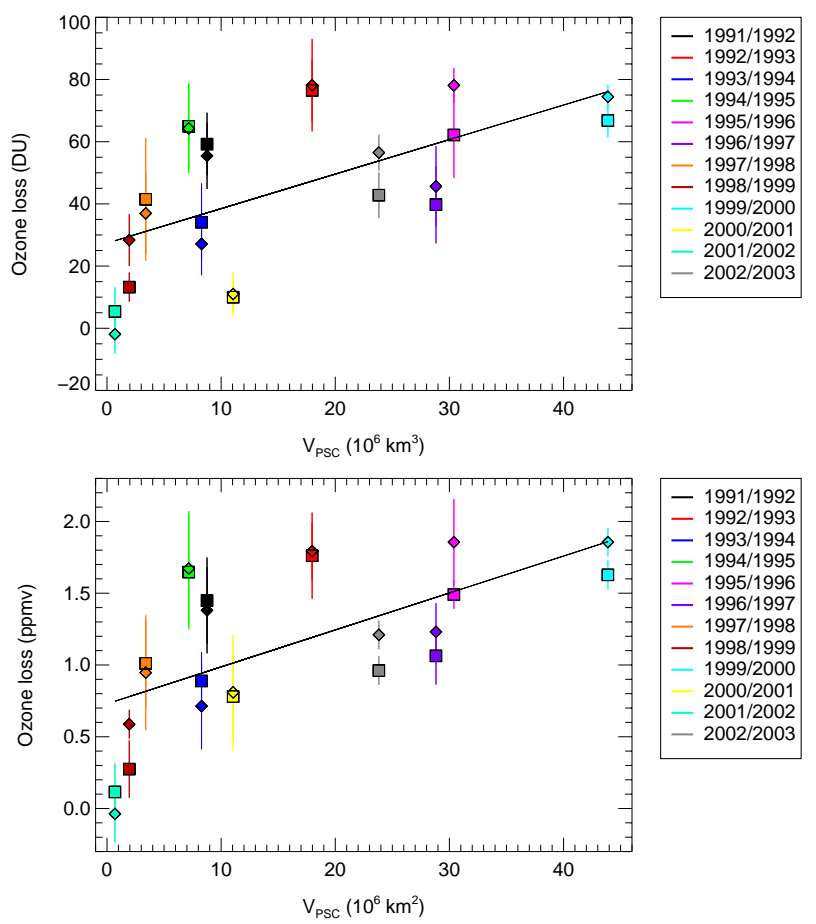

Fig. 16. Top panel: relation between the column ozone loss (DU) and $\mathrm{V}_{\mathrm{PSC}}$ in the Arctic polar vortex for the years 1991-1992 to 2002-2003 in different colours. Monthly averaged ozone loss inside the vortex core in March (February in 2000-2001 and 2002-2003) between $400-500 \mathrm{~K}$ (between $450-500 \mathrm{~K}$ inside the entire vortex in winter 2000-2001) using the TRAC method; coloured solid squares ( $\mathrm{HF}$ is used as the long-lived tracer) and solid diamonds $\left(\mathrm{CH}_{4}\right.$ is used as the long-lived tracer). $\mathrm{V}_{\text {PSC }}$ was averaged between the time of the early winter reference function of each year and the end of March between 400-550 K derived from UKMO data. Black line indicates a linear relation between $\mathrm{V}_{\mathrm{PSC}}$ and ozone loss. Bottom panel: as top panel, but for the accumulated ozone loss in mixing ratio in the altitude range $400-500 \mathrm{~K}$ derived only from HALOE observations is shown.

consider the deviation of ozone loss values from the linear relation between ozone loss and $\mathrm{V}_{\text {PSC }}$ (black lines in Fig. 16, that is a fit through the entire set of values). We will hereafter refer to this quantity as the "ozone loss anomaly". In Fig. 17, the ozone loss anomaly is plotted against sun hours per day. The latter quantity was calculated only for the cold parts of the vortex (that is only for temperatures below the PSC threshold). Daily sun hours at possible $A_{P S C}$ were averaged in a time interval between the time of early winter reference function and the end of March between 400-550 K. Excluding the winters 1991-1992 and 1992-1993 (strong influence of volcanic eruption) and 2000-2001 and 2001-2002 (uncertain results) a linear relation between the ozone loss anomaly and sun hours per day is obvious. The slope is $8.9 \mathrm{DU}$ per sun hour with $\sigma=9.1 \mathrm{DU}$ considering the accumulated ozone loss. Considering ozone loss in mixing ratios, the slope is 

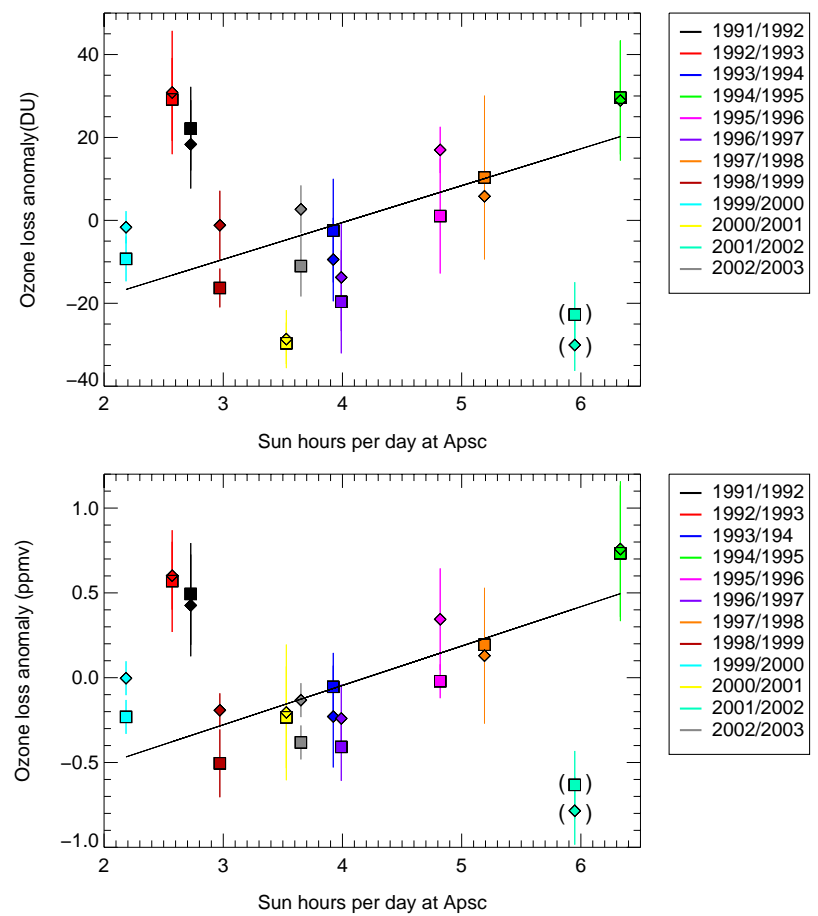

Fig. 17. Top panel: deviation of column ozone loss (DU) from the linear relation (black line in Fig. 16, top panel) in relation to sun hours per day at ( $\mathrm{A}_{\mathrm{PSC}}$ ) (see text). Bottom panel: deviation of accumulated ozone loss in mixing ratio from the linear relation (black line in Fig. 16, bottom panel) in relation to sun hours per day at (APSC) (see text).

0.23 ppmv with $\sigma=0.22$ ppmv (Fig. 17, black lines). The effect of different durations of illumination on the cold parts of the polar vortex is therefore significant. An increase in sun hours per day of $4 \mathrm{~h}$ may result in an increase of $\approx 36 \mathrm{DU}$ column ozone loss inside the vortex core, or $\approx 0.9 \mathrm{ppmv}$ averaged ozone loss in 400-500 K.

However, the influence of the duration of illumination does not describe the entire deviation from a linear ozone loss to $\mathrm{V}_{\text {PSC }}$ relation. The ozone anomalies in winters 1991-1992 and 1992-1993 scatter above the derived linear relation in Fig. 17, black line, as described above. These anomalies may be caused by the strong increase in background sulphate aerosols after the major volcanic eruption of Mount Pinatubo on 15 June 1991. Heterogeneous chemical reactions occur on the surface of these particles, which increases the chlorine activation and, therefore, the amount of ozone loss (Solomon, 1999; Dessler, 2000). The strongest ozone anomaly, more than $\approx 40$ DU (in $400-500 \mathrm{~K}$ ), is found for winters 19911992 and 1992-1993. We would expect a stronger anomaly in winter 1991-1992 compared to 1992-1993, but this is not the case. In winter 1992-1993, VPSC is more than twice as large as in winter 1991-1992 (see Fig. 16), therefore the winter was colder for a longer period and the influence of sulphate aerosols may be stronger. Further, the polar vortex in winter 1991-1992 may be influenced by mixing processes owing to a major warming event at the end of January (see Sect. 2.2). This may lead to an underestimation that may be the reason for lower ozone loss in 1991-1992 compared to 1992-1993. The effect of the volcanic eruption can no longer be seen in winter 1993-1994. No further effects including chemical ozone loss could be found in this study.

\section{Discussion}

The ozone-tracer correlation technique (TRAC) was applied to measurements in the Arctic polar region made by HALOE from 1991-1992 to 2002-2003. The accumulated local ozone loss in $380-550 \mathrm{~K}$, the average in $400-500 \mathrm{~K}$, the maximum of local ozone loss, and the column ozone loss (in 380$550 \mathrm{~K}$ ) was derived for different months using HALOE observations. A comprehensive error analysis was performed.

Early winter reference functions for the ozone-tracer relation for all winters between 1991-1992 and 2002-2003 were derived with the TRAC technique. The meteorological conditions in a particular winter have a strong impact on the ozone-tracer and $\mathrm{HCl}$-tracer relations. If the temperatures inside the vortex are low enough strong chlorine activation is identified through the very small $\mathrm{HCl}$ mixing ratios in the HCl-tracer relation. Available measurements made by the HALOE instrument indicate a strong ozone loss occurring in the weeks following a period of strong chlorine activation. On the other hand, strong chlorine activation during February and March does not necessarily cause strong ozone destruction. In years when the vortex was weakening and getting warmer (for example in 1993-1994 and 2000-2001) a pronounced chlorine activation in February and March did not result in further ozone destruction and the observed ozone loss is rather small. Thus, ozone loss occurs with a temporal delay after chlorine activation.

With the recovery of chlorine chemistry, as observed for example in April 1991-1992 to 1995-1996, ozone loss comes to a halt. If the vortex or remnants of the vortex are still isolated in April, a deviation from the ozone-tracer reference function remains unaltered from the conditions observed earlier in the year inside the vortex (as in 1992-1993, 1995-1996) or, if the vortex remnants exist long enough, additional ozone loss may occur due to $\mathrm{NO}_{\mathrm{x}}$ chemistry (as in May 1996-1997). The mixing in of air from outside the vortex due to the break-up of the vortex results in a decrease of the deviation from the reference function as observed in 1994-1995.

The TRAC technique also permits the homogeneity of ozone loss inside the vortex to be described for the twelveyear period investigated here. For example, in winter 19961997 the calculated ozone losses show a strong inhomogeneity of ozone loss inside the entire vortex (Tilmes et al., 2003b). 
Very homogeneous distributions of ozone loss inside the vortex core, for example in 1992-1993, 1999-2000 and 2002-2003, indicate that the vortex core was well isolated up to the time when the observations were made and that the meteorological conditions inside the vortex were fairly homogeneous. A more inhomogeneous distribution of the temperature inside the entire vortex results in a larger value of the standard deviation of the calculated ozone loss. Thus, inhomogeneous ozone loss profiles indicate an inhomogeneous temperature distribution inside the entire vortex. Further, the TRAC method allows a differentiation to be made between ozone loss inside the vortex core and inside the outer vortex.

A major proportion of the uncertainties in the final results are due to the uncertainty of this reference function, which arises owing to the scatter of profiles used and the lack of observations. The time chosen to derive the early winter reference function strongly depends on the availability of observations inside the early vortex. These are, in most years, limited due to the incomplete temporal coverage of measurement inside high northern latitudes. The smallest error of the ozone loss determined due to the uncertainty of the reference function is $\approx 10 \%$ in the cold winter $1995-1996$ and $\approx 15 \%$ in the cold winter 1999-2000. In the other cold and moderately cold winters, the error is $20-40 \%$. The error for the winters with little ozone loss (1998-1999 and 2000-2001) is about 50\%. In winter 2001-2002, the error is even greater than the deduced ozone loss of less than 10 DU ozone loss so that the results derived here are compatible with zero ozone loss.

Thus, very small ozone losses cannot be determined with sufficient accuracy by the TRAC method. The more reliably the early winter reference function can be derived, owing to the availability of measurements inside the early vortex, and the more ozone is destroyed in the course of the winter, the more certain the calculated ozone loss is. In summary, the application of the TRAC method permits chemical ozone loss to be calculated as a function of the variability of different meteorological conditions inside the range of uncertainty denoted.

A comparison of the results derived by the TRAC technique and the results derived by the techniques using meteorological models to simulate the transport processes in the stratospheric Arctic vortex was performed. The calculated column ozone loss and local accumulated ozone loss determined in the present work are in agreement with the results of previous studies for the cold and undisturbed vortex in winter 1999-2000. The column ozone loss derived from SAOZ/REPROBUS in 1993-1994, 1994-1995, 19951996, 1997-1998 and 1998-1999 agrees well with results obtained by TRAC using HALOE within the reported uncertainties, if calculated between January and March. Results of the winters 1996-1997, 1999-2000 and 2001-2002 deduced by SAOZ are somewhat larger compared to TRAC using HALOE measurements. The very strong ozone loss rates calculated by SAOZ during the early winter in Decem- ber and first part of January in winter 1993-1994 and 19951996 were not obtained by the TRAC method using HALOE data in the vortex boundary region. Further, the issue of the unexpected large ozone loss rates during January in the winters 1995, 1996 and 2000 based on data from Match, POAM II and POAM III and MLS cannot be addressed using the TRAC method. In the other winters, results estimated by the TRAC technique are in agreement with the results derived from MLS measurements in the altitude range of 400-550 K, if similar time intervals were considered in winters 19921993, 1993-1994, 1995-1996 and 1996-1997. Differences can be explained by different time intervals over which ozone loss was estimated. Comparing the accumulated local ozone loss of these two approaches HALOE results are in general larger in $465 \mathrm{~K}$.

Furthermore, the results of the TRAC method and of the vortex average approach agree quite well for all winters inside the range of uncertainty except for winters 1991-1992 and 1992-1993. Smaller differences occur due to the different time intervals considered for estimating ozone loss using the two different approaches.

Although the reported error estimates, especially for small ozone loss values, are rather large when derived using the TRAC method, the TRAC technique has a particular advantage. Using TRAC we do not need to simulate the transport processes within an in part strongly disturbed polar vortex, as has to be done with other methods.

In this study, a positive correlation between chemical ozone loss and the volume of possible PSC existence was derived using the TRAC method. This finding is in agreement with Rex et al. (2004). However, further meteorological factors controlling ozone loss could be identified if $\mathrm{V}_{\text {PSC }}$ was averaged over the same time interval as that for which the accumulated ozone loss was deduced. Besides $\mathrm{V}_{\text {PSC }}$, the duration of solar illumination onto very cold parts of the vortex is another important factor controlling chemical ozone loss. The impact of this effect in the twelve-year period reaches up to $36 \mathrm{DU}$ in column ozone loss per 4 daily sun hours between an altitude range of $400-500 \mathrm{~K}$, and $0.9 \mathrm{ppm}$ accumulated ozone loss in mixing ratios.

Further, a positive correlation between chemical ozone destruction and the content of sulphate aerosols in the atmosphere, caused by the Pinatubo volcanic eruption in 1991 is clearly noticeable.

\section{Conclusions}

Calculated ozone loss for twelve winters between 1991-1992 and 2002-2003 using the TRAC method allows the following conclusions to be drawn. Chemical ozone loss and chlorine activation in the Arctic lower stratosphere strongly depends on the volume of possible PSC existence ( $\mathrm{V}_{\mathrm{PSC}}$ ) during winter and spring. The slope of the relationship between ozone loss and $\mathrm{V}_{\text {PSC }}$ is similar to that found by Rex et al. (2004) 
using the vortex average approach. Further, solar illumination of the cold parts of the vortex is very important in the lower stratosphere as well as the amount of sulphate aerosols in the stratosphere. The influence of solar radiation on ozone loss also becomes obvious in the early vortex in January. Especially in January 1992 significant ozone losses were found due to a strong illumination of the vortex area of PSC existence.

A comparison of the deduced ozone losses from TRAC with those deduced by other methods generally shows a good agreement. Some apparent discrepancies may be explained by different time periods for which the ozone loss was deduced by TRAC and other methods. However, there is a tendency for ozone loss deduced from MLS measurements to be somewhat lower and for ozone loss deduced from SAOZ to be somewhat larger than the losses determined using TRAC. The ozone losses deduced using either Match or the vortex average approach agree best with those reported here based on a TRAC analysis of HALOE measurements.

\section{Appendix}

\section{Calculation of column ozone loss}

A detailed description of the calculation of ozone loss in the column density is given here. The column density of ozone or "column ozone" in the unit [molecules per $\mathrm{cm}^{2}$ ] is the total amount of ozone molecules per area integrated over altitude. Column ozone is usually given in Dobson units (DU); one Dobson unit is $2.69 \times 10^{16}$ molecules $/ \mathrm{cm}^{2}$. To obtain the column ozone loss, the difference between the column of measured ozone $\left(\mathrm{Col}_{\mathrm{O}_{3}}\right)$ and the column of the corresponding proxy ozone $\left(\mathrm{Col}_{\hat{\mathrm{O}}_{3}}\right)$ has to be calculated (see Sect. 4.1).

$\mathrm{Col}_{\mathrm{O}_{3 l o s s}}=\mathrm{Col}_{\hat{\mathrm{O}}_{3}}-\mathrm{Col}_{\mathrm{O}_{3}}$.

The number density of ozone $\left[\mathrm{O}_{3}\right]$ (and $\left[\hat{\mathrm{O}}_{3}\right]$ ) in molec $/ \mathrm{cm}^{3}$ has to be vertically integrated over a certain altitude range $d z$ (between the geometric heights $z_{1}$ and $z_{2}$ ) to obtain the column ozone in units molecules per $\mathrm{cm}^{2}$.

$\operatorname{Col}_{\mathrm{O}_{3 l o s s}}=\int_{z_{1}}^{z_{2}}\left[\hat{\mathrm{O}}_{3}\right] d z-\int_{z_{1}}^{z_{2}}\left[\mathrm{O}_{3}\right] d z$.

$\left[\mathrm{O}_{3}\right]$ (and $\left[\hat{\mathrm{O}}_{3}\right]$ ) can be written as the ozone mixing ratio $\mu_{\mathrm{O}_{3}}\left(\mu_{\hat{\mathrm{O}}_{3}}\right)$ multiplied by the number density of air $\mathrm{M}$ (in molec $/ \mathrm{cm}^{3}$ ). Therefore, the column ozone can be calculated as follows:

$\int_{z_{1}}^{z_{2}}\left[\mathrm{O}_{3}\right] d z=\int_{z_{1}}^{z_{2}} \mu_{\mathrm{O}_{3}} \mathrm{M} d z$.

The transformation to pressure coordinates is performed using $d p=-\rho g * d z$ :

$\int_{z_{1}}^{z_{2}}\left[\mathrm{O}_{3}\right] d z=\int_{p_{2}}^{p_{1}} \frac{1}{g} * \frac{\mathrm{M}}{\rho} \mu_{\mathrm{O}_{3}} d p$ where the acceleration of gravity $g=9.81 \mathrm{~m} / \mathrm{sec}^{-2}, \rho=$ mass density (in $\mathrm{g} / \mathrm{cm}^{3}$ ) and $p=$ pressure (in hpa).

The ratio of the density of air $\mathrm{M}$ and mass density $\rho$

$\frac{\mathrm{M}(p, T)}{\rho(p, T)}=\frac{\mathrm{N}_{\mathrm{A}}}{\mathrm{m}_{\mathrm{L}}}=$ const.

is constant $^{1}$, with the Avogadro number $\mathrm{N}_{\mathrm{A}}=6.02205 \times 10^{23} \mathrm{molec} / \mathrm{mol}$ and the molecular mass of dry air $m_{L}=29 \mathrm{~g} / \mathrm{Mol}$. Therefore,

$$
\begin{aligned}
\alpha & =\frac{1}{g} * \frac{\mathrm{M}}{\rho}=\frac{1}{g} * \frac{\mathrm{N}_{\mathrm{A}}}{\mathrm{m}_{\mathrm{L}}} \\
\alpha & =\frac{1}{981} * \frac{6.0225 * 10^{23}}{29}\left[\frac{\mathrm{molec} \cdot \mathrm{sec}^{2}}{\mathrm{~cm} \cdot \mathrm{g}}\right] \\
& =2.116 * 10^{19}\left[\frac{\mathrm{molec} \cdot \mathrm{sec}^{2}}{\mathrm{~cm} \cdot \mathrm{g}}\right] \\
& =2.116 * 10^{22}\left[\frac{\mathrm{molec}}{\mathrm{hpa} \cdot \mathrm{cm}^{2}}\right]
\end{aligned}
$$

and Eq. (4.5) becomes

$\mathrm{Col}_{\mathrm{O}_{3}}=\alpha * \int_{p_{2}}^{p_{1}} \mu_{\mathrm{O}_{3}} d p$

The column ozone in a certain altitude range may be expressed in DU:

$$
\begin{aligned}
& \int_{z_{1}}^{z_{2}}\left[\mathrm{O}_{3}\right] d z=\frac{\alpha}{2.69 * 10^{16}} * \int_{p_{2}}^{p_{1}} \mu_{\mathrm{O}_{3}} d p \\
& \int_{z_{1}}^{z_{2}}\left[\hat{\mathrm{O}}_{3}\right] d z=\frac{\alpha}{2.69 * 10^{16}} * \int_{p_{2}}^{p_{1}} \mu_{\hat{\mathrm{O}}_{3}} d p .
\end{aligned}
$$

The main uncertainty in calculating the column ozone loss in Dobson units is introduced through the first term on the right hand side of Eq. (1); the uncertainty of $\mathrm{Col}_{\hat{\mathrm{O}}_{3}}$ is largely a consequence of the uncertainty $\sigma$ of the early winter reference function (see Sect. 3.1).

Lower stratospheric ozone loss occurs at altitudes between about 350 and $550 \mathrm{~K}$ potential temperature (see Figs. 9 and 10). Thus, the calculated loss inside this altitude range is a good estimate of the ozone loss in the total column.

Acknowledgements. We would like to thank all members of the HALOE data processing teams for their work in producing a highquality data set and the UK Meteorological Office for providing meteorological analyses. We are grateful for the contribution of P. Crutzen, who originally suggested the calculation of column ozone loss with the method explained in Appendix. We thank U. Schmidt for a thorough review of the $\mathrm{PhD}$ thesis, part of which forms the basis of this paper. Further, we acknowledge D. S. McKenna and M. Riese for helpful comments and discussion.

Edited by: J. Burrows

\footnotetext{
${ }^{1}$ Because of the ideal gas law, $\mathrm{M}=\left(\mathrm{n} \cdot \mathrm{N}_{\mathrm{A}}\right) / \mathrm{V}=\left(\rho \cdot \mathrm{N}_{\mathrm{A}}\right) /(\mathrm{RT})$ and $\rho=\left(\mathrm{n} \cdot \mathrm{m}_{\mathrm{L}}\right) / \mathrm{V}=\left(\rho \cdot \mathrm{m}_{\mathrm{L}}\right) /(\mathrm{RT})$ with volume $\mathrm{V}$ and number of moles n.
} 


\section{References}

Allam, R. J., Groves, K. S., and Tuck, A. F.: Global OH distribution derived from general-circulation model fields of ozone and water-vapor, J. Geophys. Res., 86, 5303-5320, 1981.

Avallone, L. M. and Prather, M. J.: Tracer-tracer correlations: Three-dimensional model simulations and comparisons to observations, J. Geophys. Res., 102, 19233-19246, 1997.

Becker, G., Müller, R., McKenna, D. S., Rex, M., and Carslaw, K. S.: Ozone loss rates in the Arctic stratosphere in the winter 1991/92: Model calculations compared with Match results, Geophys. Res. Lett., 25, 4325-4328, 1998.

Becker, G., Müller, R., McKenna, D. S., Rex, M., Carslaw, K. S., and Oelhaf, H.: Ozone loss rates in the Arctic stratosphere in the winter 1994/1995: Model simulations underestimate results of the Match analysis, J. Geophys. Res., 105, 15 175-15 184, 2000.

Coy, L., Nash, E., and Newman, P.: Meteorology of the polar vortex: Spring 1997, Geophys. Res. Lett., 24, 2693-2696, 1997.

Deniel, C., Bevilacqua, R. M., Pommereau, J. P., and Lefèvre, F.: Arctic chemical ozone depletion during the 1994-1995 winter deduced from POAM II satellite observations and the REPROBUS three-dimensional model, J. Geophys. Res., 103, 19231-19244, 1998.

Dessler, A. E.: The chemistry and physics of stratospheric ozone, in: International Geophysics Series, edited by: Dmowska, R., Holton, J. R., and Rossby, H. T., 74, 214, Academic Press, London, San Diego, 2000.

Ehhalt, D. H., Röth, E. P., and Schmidt, U.: On the temporal variance of stratospheric trace gas concentrations, J. Atmos. Chem., 1, 27-51, 1983.

Engel, A., Schiller, C., Schmidt, U., Borchers, R., Ovarlez, H., and Ovarlez, J.: The total hydrogen budget in the Arctic winter stratosphere during the European Arctic Stratospheric Ozone Experiment, J. Geophys. Res., 101, 14 495-14 503, 1996.

Fahey, D. W., Donnelly, S. G., Keim, E. R., Gao, R. S., Wamsley, R. C., Del Negro, L. A., Woodbridge, E. L., Proffitt, M. H., Rosenlof, K. H., Ko, M. K. W., Weisenstein, D. K., Scott, C. J., Nevison, C., Solomon, S., and Chan, K. R.: In situ observations of $\mathrm{NO}_{\mathrm{y}}, \mathrm{O}_{3}$, and the $\mathrm{NO}_{\mathrm{y}} / \mathrm{O}_{3}$ ratio in the lower stratosphere, Geophys. Res. Lett., 23, 1653-1656, 1996.

Fueglistaler, S., Buss, S., Luo, B. P., Wernli, H., Flentje, H., Hostetler, C. A., Poole, L. R., Carslaw, K. S., and Peter, T.: Detailed modeling of mountain wave PSCs, Atmos. Chem. Phys., 3, 697-712, 2003.

Goutail, F., Pommereau, J.-P., Phillips, C., Deniel, C., Sarkssian, A., Lefèvre, F., Kyro, E., Rummukainen, M., Ericksen, P., Andersen, S. B., Kaastad-Hoiskar, B.-A., Braathen, G., Dorokhov, V., and Khattatov, V. U.: Depletion of column ozone in the Arctic during the winter of 1993-1994 and 1994-1995, J. Atmos. Chem., 32, 1-34, 1999.

Goutail, F., Pommereau, J.-P., and Lefèvre, F.: Winter ozone loss in the Arctic and at mid-latitudes in 1998 and 1999 from the SAOZ ground-based network and balloon measurements, in: Proc. 5th Europ. Symp., EU Air Pollution Res. Rep. 73, Saint Jean de Luz (France), 1999, edited by: Harris, N. R. P., Guirlet, M., and Amanatidis, G. T., 433-436, 2000.

Goutail, F., Pommereau, J.-P., and Lefèvre, F.: Total ozone reduction in the Arctic during the winters 2001 and 2002 from the SAOZ network and comparison to previous winters, in: Proc. 6th Europ. Symp., EU Air Pollution Res. Rep. 79, Göteborg (Swe- den) 2002, edited by: Harris, N. R. P., Amanatidis, G. T., and Levine, J. G., 181-184, 2003.

Grooß, J.-U. and Müller, R.: The impact of mid-latitude intrusions into the polar vortex on ozone loss estimates, J. Atmos. Chem., 3, 395-402, 2003.

Hansen, G., Svenøe, T., Chipperfield, M. P., Dahlback, A., and Hoppe, U.-P.: Evidence of substantial ozone depletion in winter 1995/1996 over Northern Norway, Geophys. Res. Lett., 24, 799-802, 1997.

Hanson, D. R. and Mauersberger, K.: Laboratory studies of the nitric acid trihydrate: Implications for the south polar stratosphere, Geophys. Res. Lett., 15, 855-858, 1988.

Harris, N., Rex, M., Goutail, F., Knudsen, B., Manney, G., Müller, R., and von der Gathen, P.: Comparison of empirically derived ozone loss rates in the Arctic vortex, J. Geophys. Res., 107, doi:10.1029/2001JD000 482, 2002.

Holton, J. R.: A dynamically based transport parameterization for one-dimensional photochemical models of the stratosphere, J. Geophys. Res., 91, 2681-2686, 1986.

Hoppel, K., Bevilacqua, R., Nedoluha, G., Deniel, C., Lefèvre, F., Lumpe, J., Fromm, M., Randall, C., Rosenfield, J., and Rex, M.: POAM III observations of Arctic ozone for the 1999/2000 winter, J. Geophys. Res., 107, 8262, doi:10.1029/2001JD000476, 2002.

Khosrawi, F., Müller, R., Proffitt, M. H., and Nakajima, H.: Monthly averaged ozone and nitrous oxide from the improved limb atmospheric spectrometer (ILAS) in the northern and southern hemisphere polar regions, J. Geophys. Res., 109, D10301, doi:2003JD004365, 2004.

Kilbane-Dawe, I., Harris, N., Pyle, J., Rex, M., Lee, A., and Chipperfield, M.: A comparison of Match and 3D model ozone loss rates in the Arctic polar vortex during the winters of 1994/1995 and 1995/1996, J. Atmos. Chem., 39, 123-138, 2001.

Knudsen, B. M., Larsen, N., Mikkelsen, I. S., Morcrette, J.-J., Braathen, G. O., Kyrö, E., Fast, H., Gernandt, H., Kanzawa, H., Nakane, H., Dorokhov, V., Yushkov, V., Hansen, G., Gil, M., and Shearman, R. J.: Ozone depletion in and below the Arctic vortex for 1997, Geophys. Res. Lett., 25, 627-630, 1998.

Knudsen, B. M., amd A. Garnier, J.-P. P., Nunez-Pinharanda, M., Denis, L., Hertzog, A., Newman, P., Letrenne, G., and Durand, M.: Accuracy of analyzed stratospheric temperatures in the winter Arctic vortex from infrared Montgolfier longduration balloon flights - 2. Results, J. Geophys. Res., 107, 4316, doi:10.1029/2001JD001329, 2002.

Kondo, Y., Irie, H., Koike, M., and Bodecker, G.: Denitrification and nitrification in the Arctic stratosphere during the winter of 1996-1997, Geophys. Res. Lett., 27, 337-340, 2000.

Konopka, P., Grooß, J. U., Günther, G., McKenna, D. S., Müller, R., Elkins, J. W., Fahey, D., and Popp, P.: Weak impact of mixing on chlorine deactivation during SOLVE/THESEO2000: Lagrangian modeling (CLaMS) versus ER-2 in situ observations, J. Geophys. Res., 108, 8324, doi:10.1029/2001JD000 876, 2003.

Lefèvre, F., Figarol, F., Carslaw, K. S., and Peter, T.: The 1997 Arctic ozone depletion quantified from three-dimensional model simulations, Geophys. Res. Lett., 25, 2425-2428, 1998.

Mahlman, J. D., Levy II, H., and Moxim, W. J.: Three-dimensional simulations of stratospheric $\mathrm{N}_{2} \mathrm{O}$ : Predictions for other trace constituents, J. Geophys. Res., 91, 2687-2707, 1986.

Manney, G., Froidevaux, L., Santee, M., Livesey, N., Sabutis, J., and Waters, J.: Variability of ozone loss during Arc- 
tic winter (1991 to 2000) estimated from UARS Microwave Limb Sounder measurements, J. Geophys. Res., 108, doi:10.1029/2002JD002 634, 2003a.

Manney, G., Lahoz, W., Sabutis, J., O’Neill, A., and SteenmanClark, L.: Simulations of fall and early winter in the stratosphere, Quart. J. Roy. Meteorol. Soc., in press, 2003b.

Manney, G. L. and Sabutis, J. L.: Development of the polar vortex in the 1999-2000 Arctic winter stratosphere, Geophys. Res. Lett., 27, 2589-2592, 2000.

Manney, G. L., Zurek, R. W., O’Neill, A., Swinbank, R., Kumer, J. B., Mergenthaler, J. L., and Roche, A. E.: Stratospheric warmings during February and March 1993, Geophys. Res. Lett., 21, 813-816, 1994.

Manney, G. L., Santee, M. L., Froidevaux, L., Waters, J. W., and Zurek, R. W.: Polar vortex conditions during the 1995-1996 Arctic winter: Meteorology and MLS ozone, Geophys. Res. Lett., 23, 3203-3206, 1996.

Manney, G. L., Lahoz, W. A., Swinbank, R., O’Neill, A., Connew, P. M., and Zurek, R. W., Simulation of the December 1998 stratospheric major warming, Geophys. Res. Lett., 26, 2733-2736, 1999.

McKenna, D. S., Grooß, J.-U., Günther, G., Konopka, P., Müller, R., Carver, G., and Sasano, Y.: A new Chemical Lagrangian Model of the Stratosphere (CLaMS): Part II Formulation of chemistry-scheme and initialisation, J. Geophys. Res., 107, 10.1029/2000JD000 113, 2002.

Müller, R., Crutzen, P. J., Grooß, J.-U., Brühl, C., Russel III, J. M., and Tuck, A. F.: Chlorine activation and ozone depletion in the Arctic vortex: Observations by the Halogen Occultation Experiment on the Upper Atmosphere Research Satellite, J. Geophys. Res., 101, 12 531-12 554, 1996.

Müller, R., Crutzen, P. J., Grooß, J.-U., Brühl, C., Russell III, J. M., Gernandt, H., McKenna, D. S., and Tuck, A. F.: Severe chemical ozone loss in the Arctic during the winter of 1995-1996, Nature, 389, 709-712, 1997.

Müller, R., Grooß, J.-U., McKenna, D. S., Crutzen, P. J., Brühl, C., Russell, J. M., Gordley, L., Burrows, J., and Tuck, A. F.: Chemical ozone loss in the Arctic vortex in the winter 1995-1996: HALOE measurements in conjunction with other observations, Ann. Geophys., 17, 101-114, 1999.

Müller, R., Schmidt, U., Engel, A., McKenna, D., and Proffitt, M.: The $\mathrm{O}_{3} / \mathrm{N}_{2} \mathrm{O}$ relationship from balloon-borne observations as a measure of Arctic ozone loss in 1991-1992, Q. J. R. Meteorol. Soc., 127, 1389-1412, 2001.

Müller, R., Tilmes, S., Grooß, J.-U., McKenna, D. S., Müller, M., Schmidt, U., Toon, G. C., Stachnik, R. A., Margitan, J. J., Elkins, J. W., Arvelius, J., and Russell III, J. M.: Chlorine activation and chemical ozone loss deduced from HALOE and balloon measurements in the Arctic during the winter of 1999-2000, J. Geophys. Res., 107, 8302, doi:10.1029/2001JD001 423, 2002.

Nash, E. R., Newman, P. A., Rosenfield, J. E., and Schoeberl, M. R.: An objective determination of the polar vortex using Ertel's potential vorticity, J. Geophys. Res., 101, 9471-9478, 1996.

Naujokat, B. and Labitzke, K. (Eds): Collection of reports on the stratospheric circulation during the winters 1974/75-1991/92, STEP, 1993.

Naujokat, B., Petzold, K., Labitzke, K., Lenschow, R., Rajewski, B., Wiesner, M., and Wohlfart, R.: The stratospheric winter 1991/92, the winter of the European Arctic Stratospheric Ozone
Experiment, Beilage zur Berliner Wetterkarte, Freie Universität Berlin, 1992.

Naujokat, B., Labitzke, K., Lenschow, R., Rajewski, B., Wiesner, M., and Wohlfart, R.: The stratospheric winter 1993/1994: A cold winter with some minor warmings and a final warming, Beilage zur Berliner Wetterkarte, Freie Universität Berlin, 1995a.

Naujokat, B., Labitzke, K., Lenschow, R., Rajewski, B., Wiesner, M., and Wohlfart, R.: The stratospheric winter 1994/1095: A cold winter with a strong minor warming, Beilage zur Berliner Wetterkarte, Freie Universität Berlin, 1995b.

Newman, P., Harris, N. R. P., Adriani, A., Amanatidis, G., Anderson, J., Braathen, G., Brune, W., Carslaw, K., Craig, M., DeCola, P., Guirlet, M., Hipskind, S., Kurylo, M., Küllmann, H., Larsen, N., Mégie, G., Pommereau, J.-P., Poole, L., Schoeberl, M., Stroh, F., Toon, B., Trepte, C., and Roozendael, M. V.: An overview of the SOLVE-THESEO 2000 campaign, J. Geophys. Res., 107, 8259, doi:10.1029/2001JD001303, 2002.

Pawson, S. and Naujokat, B.: The cold winters of the middle 1990s in the northern lower stratosphere, J. Geophys. Res., 104, 14 209-14 222, 1999.

Plumb, R. A. and Ko, M. K. W.: Interrelationships between mixing ratios of long-lived stratospheric constituents, J. Geophys. Res., 97, 10 145-10 156, 1992.

Proffitt, M. H., Margitan, J. J., Kelly, K. K., Loewenstein, M., Podolske, J. R., and Chan, K. R.: Ozone loss in the Arctic polar vortex inferred from high altitude aircraft measurements, Nature, 347, 31-36, 1990.

Proffitt, M. H., Solomon, S., and Loewenstein, M.: Comparison of 2-D model simulations of ozone and nitrous oxide at high latitudes with stratospheric measurements, J. Geophys. Res., 97, 939-944, 1992.

Proffitt, M. H., Aikin, K., Margitan, J. J., Loewenstein, M., Podolske, J. R., Weaver, A., Chan, K. R., Fast, H., and Elkins, J. W.: Ozone loss inside the northern polar vortex during the 1991-1992 winter, Science, 261, 1150-1154, 1993.

Rex, M., von der Gathen, P., Harris, N. R. P., Lucic, D., Knudsen, B. M., Braathen, G. O., Reid, S. J., De Backer, H., Claude, H., Fabian, R., Fast, H., Gil, M., Kyrö, E., Mikkelsen, I., Rummukainen, M., Smit, H. G., Stähelin, J., Varotsos, C., and Zaitcev, I.: In situ measurements of stratospheric ozone depletion rates in the Arctic winter 1991/1992: A Lagrangian approach, J. Geophys. Res., 103, 5843-5853, 1998.

Rex, M., Salawitch, R., Toon, G., Sen, B., Margitan, J., Osterman, G., Blavier, J.-F., Gao, R., Donnelly, S., Keim, E., Neumann, J., Fahey, D., Webster, C., Scott, D., Herman, R., May, R., Moyer, E., Gunson, M., Irion, F., Chang, A., Rinsland, C., and Bui, T.: Subsidence, mixing and denitrification of Arctic polar vortex air measured during POLARIS, J. Geophys. Res., 104, 26611 26623, 1999a.

Rex, M., von der Gathen, P., Braathen, G. O., Reid, S. J., Harris, N. R. P., Chipperfield, M., Reimer, E., Beck, A., Alfier, R., KrügerCarstensen, R., De Backer, J., Balis, D., Zerefos, Z., O' Connor, F., Dier, H., Dorokhov, V., Fast, H., Gamma, A., Gil, M., Kyrö, E., Rummukainen, M., Litynska, Z., Mikkelsen, I., Molyneux, M., and Murphy, G.: Chemical ozone loss in the Arctic winter 1994/1995 as determined by the Match technique, J. Atmos. Chem., 32, 1-34, 1999b.

Rex, M., Salawitch, R. J., Harris, N. R. P., von der Gathen, P., Schulz, G. O. B. A., Deckelman, H., Chipperfield, M., Sinnhu- 
ber, B.-M., Reimer, E., Alfier, R., Bevilacqua, R., Hoppel, K., Fromm, M., Lumpe, J., Küllmann, H., Kleinböhl, A., von König, H. B. M., Künzi, K., Toohey, D., Vömel, H., Richard, E., Aiken, K., Jost, H., Greenblatt, J. B., Loewenstein, M., Podolske, J. R., Webster, C. R., Flesch, G. J., Scott, D. C., Herman, R. L., Elkins, J. W., Ray, E. A., Moore, F. L., Hurst, D. F., Romanshkin, P., Toon, G. C., Sen, B., Margitan, J. J., Wennberg, P., Neuber, R., Allart, M., Bojkov, B. R., Claude, H., Davies, J., Davies, W., De Backer, H., Dier, H., Dorokhov, V., Fast, H., Kondo, Y., Kyrö, E., Litynska, Z., Mikkelsen, I. S., Molyneux, M. J., Moran, E., Nagai, T., Nakane, H., Parrondo, C., Ravegnani, F., Viatte, P. S. P., and Yushkov, V.: Chemical depletion of Arctic ozone in winter 1999/2000, J. Geophys. Res., 107, 8276, doi:10.1029/2001JD000533, 2002.

Rex, M., Salawitch, R. J., Santee, M. L., Waters, J. W., Chipperfield, N. R. P. H. M., and Naujokat, B.: Empirical quantification of the dynamical and chemical processes that regulate Arctic ozone during winter, Poster at the workshop on polar ozone loss, Potsdam, March 2002.

Rex, M., Salawitch, R. J., Santee, M. L., Waters, J. W., Hoppel, K., and Bevilacqua, R.: On the unexplained stratospheric ozone losses during cold Arctic Januaries, Geophys. Res. Lett., 30, 1010, doi:10.1029/2002GL016 008, 2003a.

Rex, M., Salawitch, R. J., von der Gathen, P., Harris, N. R. P., Chipperfield, M. P., and Naujokat, B.: Arctic ozone loss and climate change, Geophys. Res. Lett., 31, L04116, doi:10.1029/2003GL018844, 2004.

Richard, E. C., Aikin, K., Andrews, A. E., Daube, B. C., Gerbig, C., Wofsy, S. C., Romashkin, P. A., Hurst, D. F., Ray, E. A., Moore, F. L., Elkins, J. W., Deshler, T., and Toon, G. C.: Severe chemical ozone loss in the Arctic polar vortex during winter 1999-2000 inferred from in-situ airborne measurements, Geophys. Res. Lett., 28, 2197-2000, 2001.

Roach, W. T.: Aircraft observations in the lower sub-arctic stratosphere in winter, Meteorol. Res. Comm. Pap. 121, 1962.

Russell, J. M., Gordley, L. L., Park, J. H., Drayson, S. R., Tuck, A. F., Harries, J. E., Cicerone, R. J., Crutzen, P. J., and Frederick, J. E.: The Halogen Occultation Experiment, J. Geophys. Res., 98, 10777-10797, 1993.

Salawitch, R., Margitan, J., Sen, B., Toon, G., Osterman, G., Rex, M., Elkins, J., Ray, E., Moore, F., Hurst, D., Romashkin, P., Bevilacqua, R., Hoppel, K., Richard, E., and Bui, T.: Chemical loss of ozone during the Arctic winter of 1999-2000: an analysis based on balloon-borne observations, J. Geophys. Res., 107, 8269, doi:10.1029/2001JD000620, 2002.

Sankey, D. and Shepherd, T. G.: Correlation of long-lived chemical species in a middle atmosphere general circulation model, J. Geophys. Res., 108, 4494, doi:10.1029/2002JD002 799, 2003.

Santee, M. L., Manney, G. L., Waters, J. W., and Livesey, N. J.: Variations and climatology of clo in the polar lower stratosphere from uars microwave limb sounder measurements, J. Geophys. Res., 108, 4454, doi:10.1029/2002JD003 335, 2003.
Schmidt, U., Kulessa, G., Klein, E., Röth, E.-P., Fabian, P., and Borchers, R.: Intercomparison of balloon-borne cryogenic whole air samplers during the MAP/GLOBUS 1983 campaign, Planet. Space Sci., 35, 647-656, 1987.

Schulz, A., Rex, M., Steger, J., Harris, N. R. P., Braathen, G. O., Reimer, E., Alfier, R., Beck, A., Alpers, M., Cisneros, J., Claude, H., De Backer, H., Dier, H., Dorokhov, V., Fast, H., Godin, S., Hansen, G., Kanzawa, H., Kois, B., Kondo, Y., Kosmidis, E., Kyrö, E., Litynska, Z., Molyneux, M. J., Murphy, G., Nakane, H., Parrondo, C., Ravegnani, F., Varotsos, C., Vialle, C., Viatte, P., Yushkov, V., Zerefos, C., and von der Gathen, P.: Match observations in the Arctic winter 1996/1997: High stratospheric ozone loss rates correlate with low temperatures deep inside the polar vortex, Geophys. Res. Lett., 27, 205-208, 2000.

Simpson, I. J., Blake, D. R., and Rowland, F. S.: Implications of the recent fluctuations in the growth rate of tropospheric methane, Geophys. Res. Lett., 29, 10, doi:10.1029/2001GL014521, 2002.

Solomon, S.: Stratospheric ozone depletion: A review of concepts and history, Rev. of Geophys., 37, 275-316, 1999.

Terao, Y., Sasano, Y., Nakajima, H., Tanaka, H., and Yasunari, T.: Stratospheric ozone loss in the 1996/1997 Arctic winter: Evaluation based on multiple trajectory analysis for doublesounded air parcels by ILAS, J. Geophys. Res., 107, 8210, doi:10.1029/2001JD000615, 2002.

Tilmes, S.: Chemical Ozone Loss in the Arctic Polar Stratosphere Derived from Satellite Observations, PhD thesis, Johann Wolfgang Goethe Universität, Frankfurt, 2003.

Tilmes, S., Müller, R., Grooß, J.-U., Höpfner, M., Toon, G. C., and Russell, J.: Very early chlorine activation and ozone loss in the Arctic winter 2002-2003, Geophys. Res. Lett., 30, 2200, doi:10.1029/2003GL018, 792, 2003a.

Tilmes, S., Müller, R., Grooß, J.-U., McKenna, D., Russell, J., and Sasano, Y.: Calculation of chemical ozone loss in the Arctic winter 1996-1997 using ozone-tracer correlations: comparison of ILAS and HALOE results, J. Geophys. Res., 108, 4045, doi:10.1029/2002JD002, 213, 2003b.

Toon, G. C., Blavier, J.-F., Sen, B., Margitan, J. J., Webster, C. R., May, R. D., Fahey, D., Gao, R., Del Negro, L., Proffitt, M., Elkins, J. W., Romashkin, P. A., Hurst, D. F., Oltmans, S., Atlas, E., Schauffler, S., Flocke, F., Bui, T. P., Stimpfle, R. M., Bonne, G. P., Voss, P. B., and Cohen, R. C.: Comparison of MkIV balloon and ER-2 aircraft measurements of atmospheric trace gases, J. Geophys. Res., 104, 26 779-26790, 1999.

von der Gathen, P., Rex, M., Harris, N. R. P., Lucic, D., Knudsen, B. M., Braathen, G. O., De Backer, H., Fabian, R., Fast, H., Gil, M., Kyrö, E., Mikkelsen, I. S., Rummukainen, M., Stähelin, J., and Varotsos, C.: Observational evidence for chemical ozone depletion over the Arctic in winter 1991-1992, Nature, 375, 131134, 1995.

WMO: Scientific Assessment of Ozone Depletion: 2002, Report No. 47, Geneva, 2003. 